Scientific paper

\title{
Effect of Mercapto and Methyl Groups on the Efficiency of Imidazole and Benzimidazole-based Inhibitors of Iron Corrosion
}

\author{
Ingrid Milošev, ${ }^{1, *}$ Nataša Kovačević ${ }^{1,2}$ and Anton Kokalj ${ }^{1}$ \\ ${ }^{1}$ Jožef Stefan Institute, Department of Physical and Organic Chemistry, \\ Jamova 39, SI-1000, Ljubljana, Slovenia \\ ${ }^{2}$ Present address: Kolektor Group d.d.o., Vojkova ulica 10, SI-5280 Idrija, Slovenia \\ * Corresponding author: E-mail: ingrid.milosev@ijs.si, URL: http://www.ijs.si/ijsw/K3-en/Milosev \\ el: +386-1-477-34-52; Fax: +386-1-251-93-85,
}

Received: 05-02-2016

Paper submitted for the Special Issue of the Acta Chimica Slovenica dedicated to Professor Janko Jamnik

\begin{abstract}
We report on the combined experimental and computational study of imidazole- and benzimidazole-based corrosion inhibitors containing methyl and/or mercapto groups. Electrochemical measurements and long-term immersion tests were performed on iron in $\mathrm{NaCl}$ solution, whilst computational study explicitly addresses the molecular level details of the bonding on iron surface by means of density functional theory calculations (DFT). Experimental data were the basis for the determination of inhibition efficiency and mechanism. Methyl group combined with mercapto group has a beneficial effect on corrosion inhibition at all inhibitor concentrations. The beneficial effect of mercapto group combined with benzene group is not so pronounced as when combined with methyl group. The latter is in stark contrast with the behaviour found previously on copper, where the effect of methyl group was detrimental and that of mercapto and benzene beneficial. Explicit DFT calculations reveal that methyl-group has a small effect on the inhibitor-surface interaction. In contrast, the presence of mercapto group involves the strong S-surface bonding and consequently the adsorption of inhibitors with mercapto group is found to be more exothermic.
\end{abstract}

Keywords: Iron; corrosion, imidazole inhibitors, polarization resistance, X-ray photoelectron spectroscopy, density functional theory (DFT)

\section{Introduction}

The inhibition of corrosion using corrosion inhibitors has been for decades one of the most important method of corrosion protection. Inhibitors are usually organic compounds which when added in small concentrations form a surface layer that protects the underlying metal surface from dissolution and, consequently, decreases the corrosion rate. Among the most important inhibitors for copper are benzotriazole and also imidazole-based inhibitors. In this study we test the applicability of several imidazole-type molecules as corrosion inhibitors for iron in $\mathrm{NaCl}$ solution.

In our previous publications a combined experimental and computational study on copper was performed. ${ }^{1,2}$
Electrochemical and immersion study, combined with topography and X-ray photoelectron spectroscopy (XPS) analyses, was carried out in chloride solution with and without the addition of various imidazole derivatives-imidazole (ImiH), 1-methyl-imidazole (ImiMe), benzimidazole $(\mathrm{BimH}), 2$-mercapto-1-methyl-imidazole (SH-Imi$\mathrm{Me})$, and 2-mercaptobenzimidazole (SH-BimH). ${ }^{1}$ The skeleton structures of these inhibitors are presented in Fig. 1. Pronounced differences were observed at concentrations $\geq 1 \mathrm{mM}$. While 1-methyl-imidazole was found to be inferior in activity to imidazole, all other derivatives were superior. At $1 \mathrm{mM}$ concentration the order of inhibition efficiency, IE, is: $\operatorname{ImiMe}<\mathrm{ImiH}<\mathrm{BimH}<\mathrm{SH}-\mathrm{ImiMe}<$ $\mathrm{SH}-\mathrm{BimH}$. The mercapto group and benzene group were shown to have a beneficial effect on corrosion inhibition, 


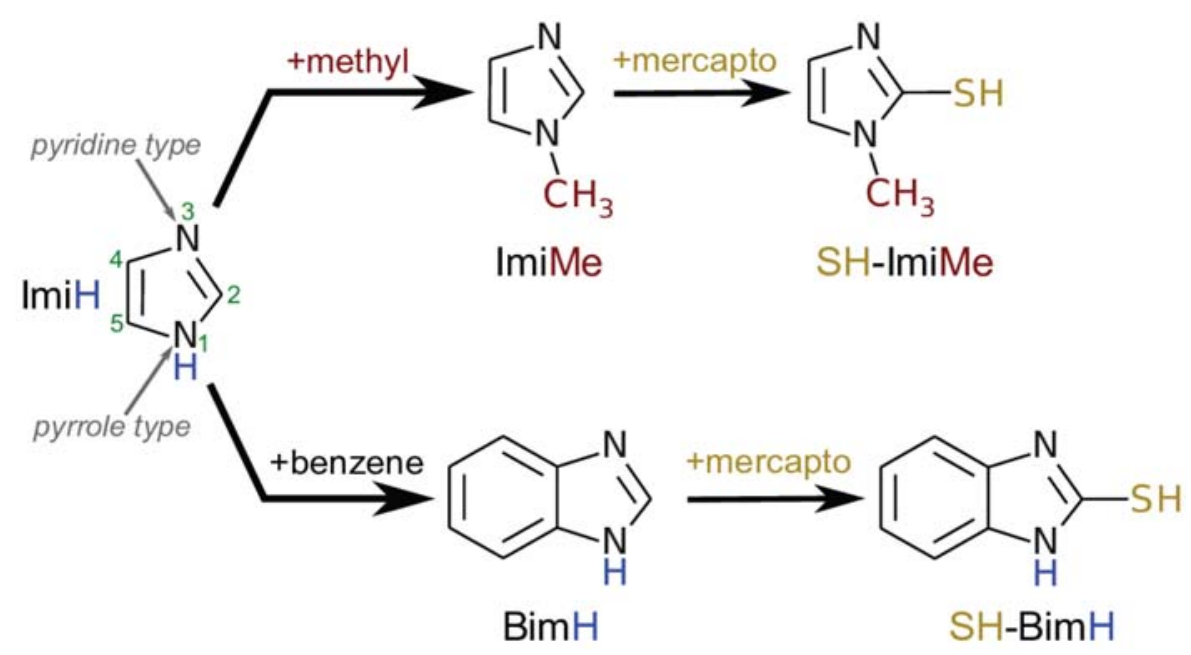

Figure 1. Skeleton structures of imidazole (ImiH), 1-methyl-imidazole (ImiMe), 2-mercapto-1-methyl-imidazole (SH-ImiMe), benzimidazole $(\mathrm{BimH})$, and 2-mercaptobenzimidazole (SH-BimH). Pyridine- and pyrrole-type $\mathrm{N}$ atoms and the numbering of atoms are also indicated.

whereas the effect of the methyl group even accelerated the corrosion at $10 \mathrm{mM}$. The protective ability of $\mathrm{BimH}$, $\mathrm{SH}-\mathrm{ImiMe}$ and $\mathrm{SH}-\mathrm{BimH}$ inhibitors is based on the formation of cuprous complexes with species originating from inhibitors, mainly carbon and nitrogen, and sulphur in the case of mercapto compounds.

Experimental study was supplemented by detailed density functional theory (DFT) calculations ${ }^{2}$ to (i) explicitly characterize the interactions between inhibitors and copper surfaces and to (ii) rationalize the experimentally observed trend. We found that mercapto-substituted imidazoles are prone to dissociation upon adsorption (S-H or $\mathrm{N}-\mathrm{H}$ bond cleavage). They bond stronger to the surface and display weaker tendency to form soluble complexes with hydrated $\mathrm{Cu}^{2+}$ ions than non-mercapto imidazoles. By encapsulating these two interactions into a simple model-the first interaction is deemed as beneficial and the second as detrimental-the inhibition efficiency trend was well captured.

Studies on iron are less common than on copper, especially in sodium chloride solution. Bhargava et al. tested different approaches - adding imidazole directly into the $3 \% \mathrm{NaCl}$ and direct deposition of inhibitor onto the metal surface prior the exposure to $\mathrm{NaCl}^{3}{ }^{3}$ The former procedure was beneficial which was explained by the interaction of imidazole's $\pi$-electron system with $\mathrm{Fe}$ such that its aromatic ring is nearly parallel to the metal surface. During direct deposition of inhibitor, however, also a pyridine type of $\mathrm{N}-\mathrm{Fe}$ interaction is present with imidazole oriented normal to the surface, as indicated by XPS. ${ }^{3}$ 2mercaptobenzimidazole ( $\mathrm{SH}-\mathrm{BimH})$ was proved to be a good corrosion inhibitor for Armco iron in $3 \% \mathrm{NaCl}$ at a maximal performance at $5 \times 10^{-3} \mathrm{~mol} \mathrm{dm}^{-3}{ }^{4}$ The SHBimH inhibition mechanism proceeds according to the Langmuir-type adsorption on the active sites and suppressing the dissolution reactions. In slightly acidic solution more studies have been performed than in neutral chloride solution. ${ }^{5-9}$ Combined electrochemical and computational HOMO/LUMO type study was performed for different imidazole-based inhibitors on iron in $1 \mathrm{M} \mathrm{HCl}^{5}$ The inhibition efficiency increased with increasing electron donating ability being the highest for amino-containing inhibitors. Heterocyclic diazoles were also shown to be good inhibitors for iron in $1 \mathrm{M} \mathrm{HCl}^{6}{ }^{6}$ Three types of iron species were identified on the inhibited surface: $\mathrm{FeOOH}$, $\mathrm{Fe}_{2} \mathrm{O}_{3}$ and $\mathrm{Fe}_{3} \mathrm{O}_{4}$. It was suggested that good inhibition agent should form an insoluble complex or surface species with low hydroxide content. Different imidazoline compounds were more strongly adsorbed on steel surface than the amidic compunds. ${ }^{7}$ Another study was performed on carbon steel in $1 \mathrm{M} \mathrm{HCl}$ containing different imidazole-based inhibitors showing the following order of inhibition efficiency: $\mathrm{BimH}>\mathrm{ImiH}>\mathrm{ImiMe} .{ }^{8} \mathrm{SH}-\mathrm{BimH}$ was shown to be adsorbed on film-free surface and the formation of oxide was ascribed to post-immersion oxidation. ${ }^{9}$ SH-ImiMe was tested on carbon steels in $1 \mathrm{M}$ $\mathrm{HClO}_{4}$ and confirmed by XPS analysis to be chemically adsorbed on steel surface. ${ }^{10}$

The present study on iron represents a comparative study to that on copper, ${ }^{1,2}$ as it is performed using the same inhibitors-ImiH, ImiMe, BimH, SH-ImiMe, and SHBimH-under the same experimental conditions. The aim of the study is twofold: (i) to compare the efficiency of inhibitors when used on copper and on iron, and (ii) to reveal the differences in inhibition mechanisms of particular inhibitors when used on copper and on iron. The methodology remains the same: experimental study was performed using electrochemical potentiodynamic measurements and immersion testing in $3 \mathrm{wt} \%$ sodium chloride solution combined with topography and XPS analyses, whilst computational study used DFT calculations to characterize the atomic scale details on the inhibitor-surface 
interactions. As a starting point and for the sake of comparison with previous publications of ours ${ }^{2,11-14}$ and those of others, ${ }^{15,16}$ where the bonding of imidazoles with bare metal surfaces was characterized, we choose to elucidate the bonding of the current inhibitor molecules with the bare $\mathrm{Fe}(110)$, although the oxidized surface of iron is way more relevant in the context of corrosion under near-neutral $\mathrm{pH}$ conditions. Current calculations are therefore more relevant for the reduced patches at the surface, where the oxide film has been breached. ${ }^{17}$ Moreover, for obvious modelling reasons we also consider the adsorption at the metal/vacuum interface, although with respect to corrosion and its inhibition, the solid/water interface is far more appropriate. Current calculations are therefore to be taken only as a first crude attempt to address the inhibitor-surface bonding. ${ }^{\text {a }}$

\section{Technical details}

\section{1. Experimental Study}

\section{1. 1. Materials and Solutions}

Corrosion tests were performed on iron metal (99.8\%, temper as rolled) supplied by Goodfellow (Cambridge Ltd., UK) in the form of $2 \mathrm{~mm}$ thick foil. All iron specimens were cut from the foil in the shape of discs of $15 \mathrm{~mm}$ diameter. Using a circulating device the specimens were ground mechanically under a stream of water with successive SiC papers of gradations 500, 800, 1000, 1200, 2400 , and 4000. The iron samples were then cleaned with acetone in an ultrasonic bath for three minutes, doublerinsed with distilled water and dried with nitrogen gas.

Samples were immersed in 3 wt. $\% \mathrm{NaCl}$ aqueous solution with or without the addition of imidazole (ImiH), 1methyl-imidazole (ImiMe), 2-mercapto-1-methylimidazole (SH-ImiMe), benzimidazole $(\mathrm{BimH})$ or 2-mercaptobenzimidazole (SH-BimH) at various concentrations $(0.1,1$, and $10 \mathrm{mM}$ ). Skeleton structures of the inhibitors are presented in Fig. 1. All five inhibitors were supplied by Sigma Aldrich (purity for ImiH 99.5\%, ImiMe 99\%, SH-ImiMe $99 \%$, BimH 98\%, and SH-BimH 98\%), and $\mathrm{NaCl}$ by Carlo Erba (pro analysis). Compounds were used as supplied.

\section{1. 2. Electrochemical Measurements}

Measurements were performed in a three-electrode corrosion cell (volume 0.25 L, Autolab, Ecochemie, Netherlands) at $25^{\circ} \mathrm{C}$. A saturated calomel electrode (SCE, $0.242 \mathrm{~V}$ with respect to the saturated hydrogen electrode at

\footnotetext{
${ }^{\text {a }}$ It should be noted that solid/vacuum interfaces and metallic surfaces are conceptually and structurally simpler than the solid/water interfaces and oxidized surfaces. This is the basic premise behind our choice, which follows the reductionist divide-and-conquer approach, i.e., start with simpler system and elaborate later.
}

$25^{\circ} \mathrm{C}$ ) with a Luggin capillary was used as a reference electrode and carbon rods as the counter-electrode. A specimen embedded in a Teflon holder, with an area of $0.785 \mathrm{~cm}^{2}$ exposed to the solution, served as the working electrode.

Measurements were carried out with a PGSTAT-12 Autolab (Metrohm Autolab, Utrecht, Netherlands) potentiostat/galvanostat operated by the NOVA software. Before measuring the polarization resistance $\left(R_{\mathrm{p}}\right)$ the iron specimens were allowed to stabilize under open circuit conditions. During that time, the open circuit potential was measured as a function of time. The stabilization process usually took $1 \mathrm{~h}$. The stable, quasi-steady state potential reached at the end of the stabilization period is denoted as the corrosion potential $\left(E_{\text {corr }}\right)$.

\section{1. 2. 1. Polarization Resistance Measurements}

Polarization resistance $\left(R_{\mathrm{p}}\right)$ was measured over a potential range of $\pm 10 \mathrm{mV}$ vs. $E_{\text {corr }}$ using a scan rate of $0.1 \mathrm{mV} / \mathrm{s} . R_{\mathrm{p}}$ values were deduced from the slope of the fitted potential vs. current density using NOVA software.

Measurements of $R_{\mathrm{p}}$ were repeated at least three times. From the average values the inhibition efficiency (IE), denoted by the symbol $\eta$, was calculated using the following equation:

$$
\eta=\frac{R_{p}^{\text {inh }}-R_{p}^{\text {blank }}}{R_{p}^{\text {inh }}} \times 100
$$

where $R_{\mathrm{p}}^{\mathrm{inh}}$ and $R_{\mathrm{p}}^{\text {blank }}$ are the polarization resistances measured with and without addition of inhibitor, repsectively. The results are presented as mean value \pm standard deviation.

\section{1. 2. 2. Potentiodynamic Measurements}

Potentiodynamic measurements were performed starting at $250 \mathrm{mV}$ negative to $E_{\text {corr }}$, then increased in the anodic direction at a potential scan rate of $1 \mathrm{mV} / \mathrm{s}$.

\section{1. 3. Immersion Test}

Iron specimens were hung in $100 \mathrm{~mL}$ closed glass vials containing 3 wt. $\% \mathrm{NaCl}$ or $3 \mathrm{wt} . \% \mathrm{NaCl}$ with the addition of $1 \mathrm{mM}$ of either ImiH, ImiMe, SH-ImiMe, BimH or SH-BimH. After immersion for one month the specimens were rinsed with deionized water and dried with nitrogen gas.

\section{1. 4. X-ray Photoelectron Spectroscopy}

X-ray photoelectron spectroscopy (XPS) was performed with a TFA Physical Electronics Inc. spectrometer using non- and mono-chromatized $\mathrm{Al} \mathrm{K}_{\alpha}$ radiation $(1486.6 \mathrm{eV})$ and a hemispherical analyzer. The monochromatized radiation used for high-resolution spectra yields a resolution of $0.6 \mathrm{eV}$, as measured on an $\mathrm{Ag} 3 \mathrm{~d}_{5 / 2}$ peak. These spectra were used to differentiate between va- 
rious species, while those obtained using non-monochromatized radiation were used to quantify the chemical composition. The take-off angle used, defined as the angle of emission relative to the surface plane, was $45^{\circ}$. The energy resolution was $0.5 \mathrm{eV}$. Survey scan spectra were recorded at a pass energy of $187.9 \mathrm{eV}$, and individual high-resolution spectra at a pass energy of $23.5 \mathrm{eV}$ with an energy step of $0.1 \mathrm{eV}$. The diameter of the analysed spot was $400 \mu \mathrm{m}$. During the analysis a small shift was observed and compensated by a neutralizer. The values of binding energies were then aligned to carbon peak C 1 s at $284.8 \mathrm{eV}$.

Angle-resolved XPS (AR-XPS) measurements were conducted at take-off angles of 20,45 and $75^{\circ}$ with respect to the surface plane to obtain depth-dependent information on the composition and structure of the layers. The depth of analysis increases with increased angle, in practice up to $10 \mathrm{~nm} .{ }^{18}$ Thus at small angles $\left(20^{\circ}\right)$ information is provided closer to the surface and, at large angles $\left(75^{\circ}\right)$, closer to the bulk.

\section{1. 5. Surface Topography}

Surface morphology was inspected using an optical microscope Olympus BX51. Surface topography was analysed employing a profilometer, model Taylor Hobson, Form Talysurf Series 2 operated by Taylor Hobson Ultra software. The instrument has a lateral resolution of $1 \mu \mathrm{m}$ and vertical resolution of $5 \mathrm{~nm}$. The surface profile is measured in one direction. Measurements were performed on three locations of each sample using a $1 \mathrm{~mm}^{2}$ spot. Data were processed with TalyMap Gold 6.2 software to create 3-D surface topography and to calculate the mean surface roughness $\left(\mathrm{S}_{\mathrm{a}}\right)$. Corrections were made to exclude general geometrical shape and possible measurement-induced misfits.

\section{2. Computational Details}

Spin-polarized DFT calculations were performed in the framework of generalized gradient approximation (GGA) of Perdew-Burke-Ernzerhof (PBE) $)^{19}$ using the plane-wave pseudo-potential method with ultra-soft pseudopotentials $^{20,21}$ as implemented in the PWscf code of the Quantum ESPRESSO distribution. ${ }^{22}$ Kohn-Sham orbitals were expanded in a plane-wave basis set up to a kinetic energy cutoff of 30 Ry (240 Ry for the charge-density cutoff).

Adsorption of molecules was modeled on denselypacked $\mathrm{Fe}(110)$ surface, which was modeled by periodic slabs consisting of four atomic layers (the structure of $\mathrm{Fe}(110)$ surface is shown in Fig. 2). The bottom layer was constrained to the bulk positions and the in-plane lattice spacing was fixed to the calculated equilibrium Fe bulk lattice parameter of $2.84 \AA \AA^{11,23}$ All other degrees of freedom were relaxed. Molecules were adsorbed on one side of the slab and the thickness of the vacuum region-the di- stance between the top of the ad-molecule and the adjacent slab-was set to about $20 \AA$. Molecular adsorption was modeled at $1 / 20 \mathrm{ML}$ monolayer (ML) coverage using the $\left(\begin{array}{cc}5 & 0 \\ -1 & 4\end{array}\right)$ supercell. ${ }^{\text {b Dipole correction of Bengtsson }}{ }^{24}$ was applied to cancel an artificial electric field that develops along the direction normal to the slab due to periodic boundary conditions imposed on the electrostatic potential. Brillouin-zone integrations were performed with Gaussin-smearing ${ }^{25}$ special point technique ${ }^{26}$ using a smearing parameter of $0.03 \mathrm{Ry}$ and a $2 \times 2 \times 1 \mathrm{k}$-point mesh. Molecular graphics were produced by the XCRYSDEN graphical package. ${ }^{27}$

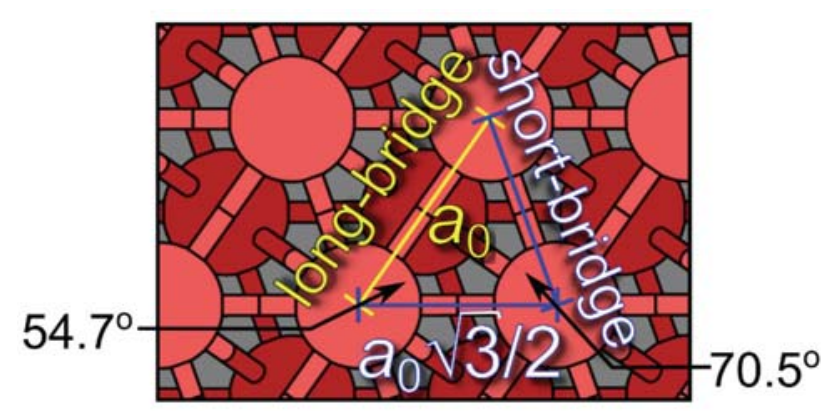

Figure 2. Structure of Fe(110) surface. Notice two different spacings between adjacent surface $\mathrm{Fe}$ atoms, termed short- and longbridge. The short-bridge distance is $a_{0} \sqrt{ } 3 / 2$, whereas long-bridge distance is $a_{0}$, where $a_{0}$ is the equilibrium bcc lattice parameter of Fe bulk. The angles between two short-bridges and between shortbridge and long-bridge are also indicated.

\section{2. 1. Definitions and Energy Equations}

The term "dehydrogenation" will be used as jargon to indicate a reaction analogous to deprotonation (MolH $\rightarrow \mathrm{Mol}^{-}+\mathrm{H}^{+}$), but with a homolytic bond cleavage (this implies that radicals are considered in favour of charged ions), i.e., $\mathrm{MolH} \rightarrow \mathrm{Mol}^{*}+\mathrm{H}^{*}$. The labels $\mathrm{MolH}, \mathrm{Mol}^{-}$, and Mol stand for neutral, deprotonated, and "dehydrogenated" inhibitor molecules, respectively (the term "dehydrogenated" designates-in analogy with "dehydrogenation"-a molecule stripped off one $\mathrm{H}$ atom); ${ }^{\mathrm{c}}$ the symbol is used to indicate the radical character of isolated dehydrogenated molecule (sometimes $\mathrm{Mol}^{*}$ will be designated simply as Mol).

The terms "non-mercapto" and "mercapto" designate the molecules without (ImiH, ImiMe, and BimH) or with the mercapto group (SH-ImiMe and SH-BimH), respectively; these shorthand labels for each inhibitor

\footnotetext{
${ }^{\mathrm{b}}$ Surface coverage in ML units is defined as the inverse of the number of surface Fe atoms per adsorbed molecule.

${ }^{\mathrm{c}}$ In contrast with the current usage of the term (removal of $\mathrm{H}$ atom), dehydrogenation is instead commonly defined as a reaction where the $\mathrm{H}_{2}$ is removed from a molecule.
} 
molecule are defined in Fig. 1. It should be noted that the two mercapto molecules can either exist in thiol or thione forms (see Fig. 3); the shorthand labels for thione form of SH-ImiMe and SH-BimH are S-ImiMeH and S$\mathrm{BimH}_{2}$, respectively, whereas dehydrogenated mercapto molecules are labeled as $\mathrm{S}-\mathrm{BimH}$ - and $\mathrm{S}-\mathrm{BimMe}$ - (or simply S-BimH and S-ImiMe). It should be noted that irrespective of the starting neutral tautomer form (thiol or thione) the resulting dehydrogenated thiolate form is the same. $^{2}$ thiol<smiles>Cn1ccnc1S</smiles>

SH-ImiMe<smiles>Sc1nc2ccccc2[nH]1</smiles>

$\mathrm{SH}-\mathrm{BimH}$

\section{thione}

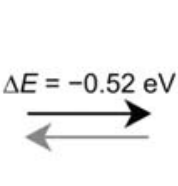<smiles>Cn1cc[nH]c1=S</smiles>

Figure 3. Skeleton structures of thiol and thione tautomers of 2mercapto-1-methyl-imidazole (top) and 2-mercaptobenzimidazole (bottom). The thiol to thione transformation involves the shifting of blue colored hydrogen atom from the S to the N3 atom. Thiones are more stable than thiols and the corresponding energy differences, calculated at the PBE/plane-wave level of theory, are stated. ${ }^{2}$

For mercapto molecules only the adsorption of thione tautomers is considered, because they are by about $0.5 \mathrm{eV}$ mores stable than thiols (as standalone) and moreover because current calculations indicate that the two thiols dissociate barrier-less or almost so (S-H bond clevage) on $\mathrm{Fe}(110)$ during adsorption.

Dehydrogenated non-mercapto molecules will be designted as Imi, ImiMe ${ }^{\mathrm{w} / \mathrm{o}-\mathrm{H}}$, and Bim for imidazole, 1methyl-imidazole, and benzimidazole, respectively. Dehydrogenated molecules will be sometimes designated as $\mathrm{Mol}_{\mathrm{X}}$, where $\mathrm{X}$ indicates at which atom the $\mathrm{X}-\mathrm{H}$ bond was cleaved.

The non-dissociative adsorption energy was calculated as:

$$
E_{\text {ads }}=E_{\mathrm{MolH} / \mathrm{slab}}-\left(E_{\mathrm{MolH}}+E_{\text {slab }}\right),
$$

where $E_{\mathrm{MolH}}, E_{\mathrm{slab}}$, and $E_{\mathrm{MolH} / \mathrm{slab}}$ are the total energies of isolated molecule, bare $\mathrm{Fe}(110)$ slab, and molecule/Fe(110) slab system, respectively. Considered molecules can dissociate on iron surface, hence the dissociative chemisorption was also considered, i.e.:

$$
\mathrm{MolH}_{(\mathrm{g})} \rightarrow \mathrm{Mol}_{(\mathrm{ads})}+\mathrm{H}_{(\mathrm{ads})},
$$

and the respective adsorption energy was calculated as:

$$
E_{\mathrm{ads}}^{\text {diss }}=E_{\mathrm{Mol} / \mathrm{slab}}+E_{\mathrm{H} / \mathrm{slab}}-\left(E_{\mathrm{MolH}}+2 E_{\mathrm{slab}}\right)
$$

where $E_{\mathrm{Mol} / \mathrm{slab}}$ and $E_{\mathrm{H} / \mathrm{slab}}$ are the total energies of the $\mathrm{Mol} / \mathrm{Fe}(110)$ and $\mathrm{H} / \mathrm{Fe}(110)$ slab systems, respectively. For mercapto molecules, the $E_{\text {ads }}$ and $E_{\text {ads }}^{\text {diss }}$ are calculated with respect to isolated thiones as a reference state for the $E_{\mathrm{MolH}}$. Note that Mol-Fe(110) bond is much stronger than indicated by the $E_{\text {ads }}^{\text {diss }}$, because the latter involves the cost for breaking the $\mathrm{X}-\mathrm{H}$ bond $(\mathrm{X}=\mathrm{N} 1$ or $\mathrm{C} 2)$. In particular, the binding energy between the dehydrogenated molecule and the surface can be calculated as:

$$
E_{\mathrm{b}}=E_{\mathrm{mol} / \mathrm{slab}}-\left(E_{\mathrm{slab}}+E_{\mathrm{Mol}}\right)
$$

where $E_{\mathrm{Mol}}$ is total energy of isolated $\mathrm{Mol}^{\circ}$ radical. The relation between the $E_{\mathrm{b}}$ and $E_{\mathrm{ads}}^{\text {diss }}$ is the following:

$$
E_{b}=E_{\mathrm{ads}}^{\mathrm{diss}}+E_{\mathrm{bond}}^{\mathrm{X}-\mathrm{H}}-E_{\mathrm{b}}^{\mathrm{H}} \text {, }
$$

where $E_{\mathrm{b}}^{\mathrm{H}}$ is the binding energy of atomic hydrogen onto $\mathrm{Fe}(110)$ and $E_{\text {bond }}^{\mathrm{X}-\mathrm{H}}$ is the bonding energy of dehydrogenated $\mathrm{X}-\mathrm{H}$ bond, $E_{\text {bond }}^{\mathrm{X}-\mathrm{H}}=E_{\mathrm{MolH}}-\left(E_{\mathrm{Mol}}+E_{\mathrm{H}}\right)$. Because the $E_{\text {bond }}^{\mathrm{X}-\mathrm{H}}$ is significantly more exothermic than $E_{\mathrm{b}}^{\mathrm{H}}$ also the $E_{\mathrm{b}}$ is significantly more exothermic than $E_{\text {ads }}^{\text {diss }}$; the calculated $E_{\mathrm{b}}^{\mathrm{H}}$ on $\mathrm{Fe}(110)$ is $-2.94 \mathrm{eV},{ }^{11}$ whereas the calculated $\mathrm{N}-\mathrm{H}$ bonding energies are in range from -3.7 to $-4.5 \mathrm{eV}$ and $\mathrm{C}-\mathrm{H}$ bonding energies are about $-5.1 \mathrm{eV}$ for the current molecules.

Dehydrogenation reaction energy $\left(\Delta E_{\mathrm{deh}}\right)$ is calculated by considering the following reaction:

$$
\mathrm{MolH}_{(\mathrm{ads})}=\mathrm{Mol}_{(\mathrm{ads})}+\mathrm{H}_{(\mathrm{ads})}
$$

hence:

$$
\begin{aligned}
\Delta E_{\mathrm{deh}} & =E_{\mathrm{Mol} / \mathrm{slab}}+E_{\mathrm{H} / \mathrm{slab}}-E_{\mathrm{MolH} / \mathrm{slab}}-E_{\mathrm{slab}} \\
& =E_{\mathrm{ads}}^{\mathrm{diss}}-E_{\mathrm{ads}}
\end{aligned}
$$

where $E_{\text {ads }}^{\text {diss }}$ is calculated by Eq (4) and $E_{\text {ads }}$ by Eq (2).

\section{Results and Discussion}

\section{1. Experimental Results}

\section{1. 1. Experimental Determination of Inhibition Efficiency of Imidazole and Benzimidazole Derivatives}

The inhibitory action of the ImiH, ImiMe, SH-Imi$\mathrm{Me}, \mathrm{BimH}$, and SH-BimH inhibitors against corrosion of iron in $3 \mathrm{wt} . \% \mathrm{NaCl}$ solution was analysed by means of 
polarization resistance $\left(R_{\mathrm{p}}\right)$, by potentiodynamic curves and by one-month immersion testing.

\section{1. 1. 1. Polarization Resistance Measurements}

Iron in uninhibited sodium chloride solution exhibited a mean $R_{\mathrm{p}}$ of $797 \Omega \mathrm{cm}^{2}$ (Table 1 ). Polarization resistance was then measured at $0.1,1$ and $10 \mathrm{mM}$ concentrations of inhibitors. In the presence of inhibitor the values increased, for example from $868 \Omega \mathrm{cm}^{2}$ for ImiH at $1 \mathrm{mM}$ to a maximum of $2851 \Omega \mathrm{cm}^{2}$ for ImiMe at $10 \mathrm{mM}$ (Table 1).

Table 1. Values of polarization resistance, $R_{\mathrm{p}}$, measured for iron in $3 \mathrm{wt} \% \mathrm{NaCl}$ solution with and without addition of $0.1,1$ and $10 \mathrm{~m}$ $\mathrm{M}$ of imidazole (ImiH) and its derivatives: 1-methyl-imidazole (ImiMe), 2-mercapto-1-methyl-imidazole (SH-ImiMe), benzimidazole $(\mathrm{BimH})$, and 2-mercaptobenzimidazole (SH-BimH). Polarization resistance is given as mean value \pm standard deviation. For $\mathrm{SH}-\mathrm{BimH}$, the $10 \mathrm{mM}$ concentration could not be prepared due to its low solubility in water.

\begin{tabular}{lcc}
\hline Solution & $\begin{array}{c}\text { Inhibitor } \\
\text { concentration }(\mathbf{m M})\end{array}$ & $\begin{array}{c}\text { Polarization } \\
\text { resistance }\left(\boldsymbol{\Omega} \mathbf{~ c m}^{\mathbf{2}}\right)\end{array}$ \\
\hline $\mathrm{NaCl}$ & - & $797 \pm 56$ \\
$+\mathrm{ImiH}$ & 0.1 & $662 \pm 41$ \\
& 1 & $868 \pm 48$ \\
$+\mathrm{ImiMe}$ & 10 & $2483 \pm 302$ \\
& 0.1 & $787 \pm 38$ \\
& 1 & $2586 \pm 64$ \\
$+\mathrm{SH}-\mathrm{ImiMe}$ & 10 & $2766 \pm 143$ \\
& 0.1 & $1030 \pm 505$ \\
$+\mathrm{BimH}$ & 1 & $1861 \pm 255$ \\
& 10 & $2851 \pm 651$ \\
& 0.1 & $910 \pm 93$ \\
$+\mathrm{SH}-\mathrm{BimH}$ & 1 & $1530 \pm 791$ \\
& 10 & $1340 \pm 555$ \\
& 0.1 & $1107 \pm 323$ \\
& 1 & $1351 \pm 251$ \\
\hline
\end{tabular}

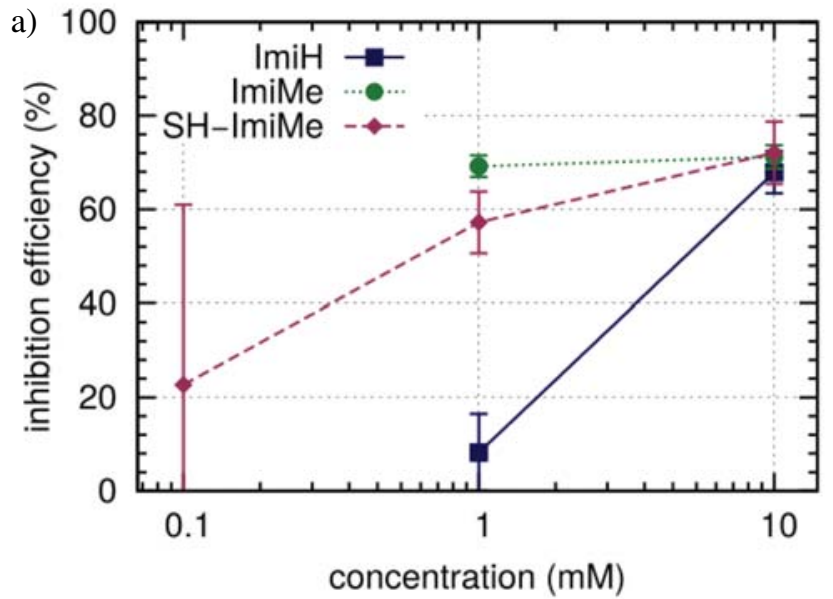

Based on the measured $R_{\mathrm{p}}$ values the IE values were calculated according to $\mathrm{Eq}$ (1) and are presented in Fig. 4. ImiH showed measurable IE only at concentration of $1 \mathrm{mM}$, and reached $68 \%$ at $10 \mathrm{mM}$ (Fig. $4 \mathrm{a}$ ). For ImiMe, however, inhibition was high already at $1 \mathrm{mM}$; the value at $10 \mathrm{mM}$ was similar as for ImiH. When in addition to methyl group, also mercapto group was present in SH-ImiMe, the inhibitor was weakly effective already at $0.1 \mathrm{mM}$ and IE increased linearly with increasing concentration. At $10 \mathrm{mM}$, similar values were obtained for all three inhibitors (Fig. 4a). This behaviour is different to that observed for copper, ${ }^{1}$ where at concentrations above $1 \mathrm{mM}$ the ImiMe acted as corrosion accelerator, and SH-ImiMe achieved $65 \%$ IE.

When adding BimH, low but measurable IE of $13 \%$ was obtained already the $0.1 \mathrm{mM}$. IE peaked at $1 \mathrm{mM}$ and then decreased at higher concentration (Fig. 4b). In the case of copper, ${ }^{1}$ BimH was the most efficient inhibitor at 10 $\mathrm{mM}$. When using both mercapto-based imidazole inhibitors the IE values were larger already at low inhibitor concentration of $0.1 \mathrm{mM}$ (Fig. 4). For SH-ImiMe, the IE ranged between $23 \%$ and $72 \%$ (Fig. 4a). SH-BimH behaved similar as BimH and reached smaller IE than SH-ImiMe (Fig. 4b); however, $10 \mathrm{mM}$ solution of $\mathrm{SH}-\mathrm{BimH}$ could not be prepared due to its low solubility in water $(<0.1$ $\mathrm{g} / 100 \mathrm{~mL}=6.7 \mathrm{mM}$ at $23.5 \mathrm{C}) .^{28}$

According to the polarisation resistance, the efficiency of inhibitors is as follows. At $0.1 \mathrm{mM}$ only mercapto-based inhibitors are useful as corrosion inhibitors but show relatively low IE of 23 and $28 \%$ for SH-ImiMe and $\mathrm{SH}$-BimH, respectively. At $1 \mathrm{mM}$ the following order was observed: ImiMe $>$ SH-ImiMe $>$ BimH $\sim$ SH-BimH $>>$ ImiH. Thus, methyl-derivative of imidazole acts as the most efficient corrosion inhibitor at $1 \mathrm{mM}$. At $10 \mathrm{mM}$ all inhibitors without benzene group show rather similar IE values (between 64 and 78\%).

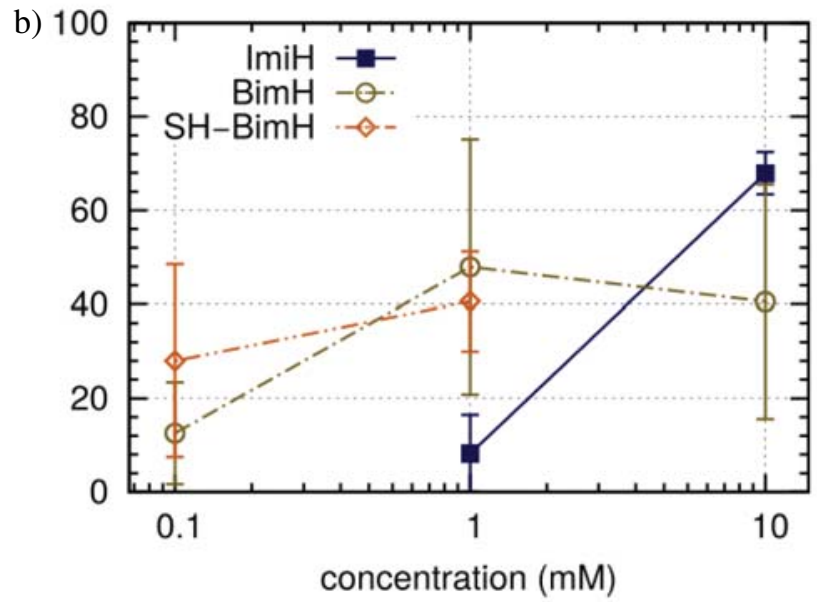

Figure 4. Inhibition efficiency against corrosion of iron in 3 wt.\% NaCl solution of imidazole (ImiH) compared to that of (a) 1-methyl-imidazole (ImiMe) and 1-methyl-2-mercapto-imidazole (SH-ImiMe), and (b) benzimidazole (BimH) and 2-mercaptobenzimidazole (SH-BimH) as a function of inhibitor concentrations $(0.1,1$, and $10 \mathrm{mM})$. Lines are drawn to guide the eye. ImiH and ImiMe do not inhibit corrosion at $0.1 \mathrm{mM}$ inhibitor concentration, whereas the solubility of $\mathrm{SH}-\mathrm{BimH}$ is below $10 \mathrm{mM}$. 


\section{1. 1. 2. Potentiodynamic Polarization Curves}

The results of the potentiodynamic measurements obtained for iron in $3 \mathrm{wt} \% \mathrm{NaCl}$ solution with and without addition of $0.1,1$, and $10 \mathrm{mM}$ concentrations of Imi$\mathrm{H}$, ImiMe, SH-ImiMe, BimH, and SH-BimH are presented in Fig. 5.

The cathodic reaction in $\mathrm{NaCl}$ solution is the reduction of oxygen:

$$
\mathrm{O}_{2}+2 \mathrm{H}_{2} \mathrm{O}+4 e^{-} \rightarrow 4 \mathrm{OH}^{-}
$$

The passivation of iron proceeds in two stages, i.e. a lower oxidation state film of $\mathrm{Fe}_{3} \mathrm{O}_{4}$ is required, and this film is highly susceptible to chemical dissolution. ${ }^{29}$ Until the conditions are established whereby the $\mathrm{Fe}_{3} \mathrm{O}_{4}$ phase can exist on the surface for a reasonable period of time, the $\gamma-\mathrm{Fe}_{2} \mathrm{O}_{3}$, which is responsible for full passivation of iron, will not form. ${ }^{29}$ Therefore, active dissolution of iron will continue. It is generally accepted that the active dissolution of iron occurs via an oxide intermediate, possible $\mathrm{Fe}(\mathrm{OH})_{2}$ or $\mathrm{Fe}(\mathrm{OH})_{2}$, which is not a three-dimensional oxide phase. ${ }^{30}$ At sufficiently high potentials, the conversion of this oxide intermediate into a true three-dimensional passive oxide is favoured over its dissolution. ${ }^{29}$

The kinetics of dissolution of iron in the active range in the presence of halide ions like chloride ions is largely dominated by competitive adsorption of $\mathrm{Cl}^{-}$with the $\mathrm{OH}^{-}$ions: ${ }^{3}$

$$
\begin{aligned}
& \mathrm{Fe}+\mathrm{H}_{2} \mathrm{O} \rightleftharpoons \mathrm{Fe}(\mathrm{OH})_{\text {ads }}+\mathrm{H}^{+}+\mathrm{e}^{-} \\
& \mathrm{Fe}(\mathrm{OH})_{\text {ads }} \rightleftharpoons \mathrm{FeOH}^{+}+\mathrm{e}^{-} \\
& 3 \mathrm{FeOH}^{+}+\mathrm{H}_{2} \mathrm{O} \rightleftharpoons \mathrm{Fe}_{3} \mathrm{O}_{4}+5 \mathrm{H}^{+}+2 \mathrm{e}^{-}
\end{aligned}
$$

At potentials close to $E_{\text {corr }}$ the anodic reaction is under mixed charge transfer and mass transport control (rate of movement of iron complex away from the surface to bulk electrolyte) while at higher anodic potentials (above $-0.4 \mathrm{~V}$ ) the anodic reaction is under diffusion control leading to the establishment of current plateau at high current density. Therefore, under the conditions of chloride solution iron is not passivated but continues to dissolve.

Addition of $0.1 \mathrm{mM}$ concentration of either ImiH, ImiMe, SH-ImiMe, BimH, or SH-BimH in 3 wt. $\% \mathrm{NaCl}$ solution induces a slight decrease in the cathodic current density and a shift of the $E_{\text {corr }}$ value to somewhat more positive values (Fig. 5a), indicating increased resistance to general iron corrosion. Curves for all inhibitors are rather similar. The effect of inhibitor type becomes more pronounced at $1 \mathrm{mM}$ concentration (Fig. 5b), especially for $\mathrm{SH}-\mathrm{ImiMe}, \mathrm{BimH}$ and SH-BimH. The current density in the anodic part of the curve is largely reduced at potentials more positive than $-0.6 \mathrm{~V}$ indicating suppressed iron dissolution. Compared to $R_{\mathrm{p}}$ values obtained in the range around $E_{\text {corr }}$, where ImiMe showed larger values (Fig. 4), mercapto-based inhibitors exhibited better inhibitive ef- a) $0.1 \mathrm{mM}$ inhibitor

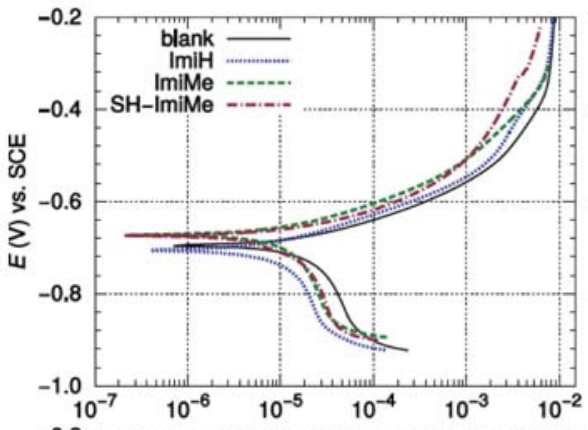

b) $1 \mathrm{mM}$ inhibitor
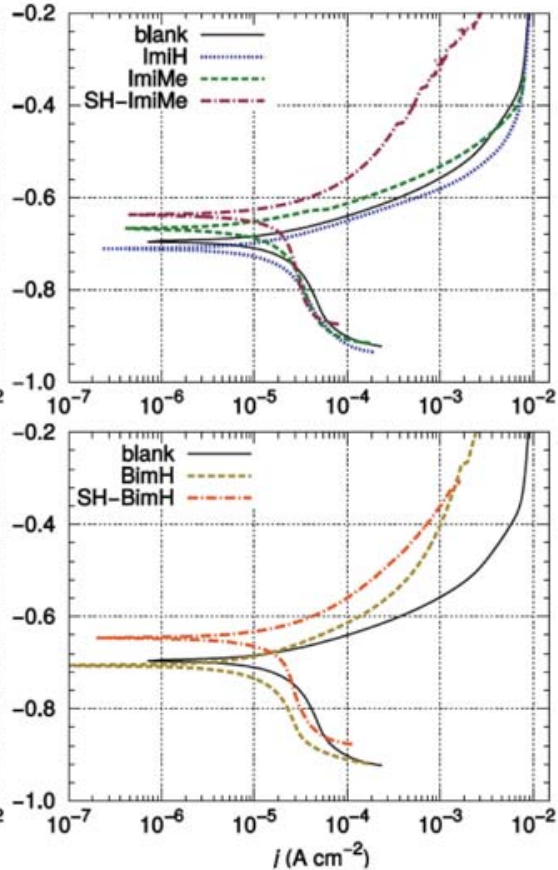

c) $10 \mathrm{mM}$ inhibitor
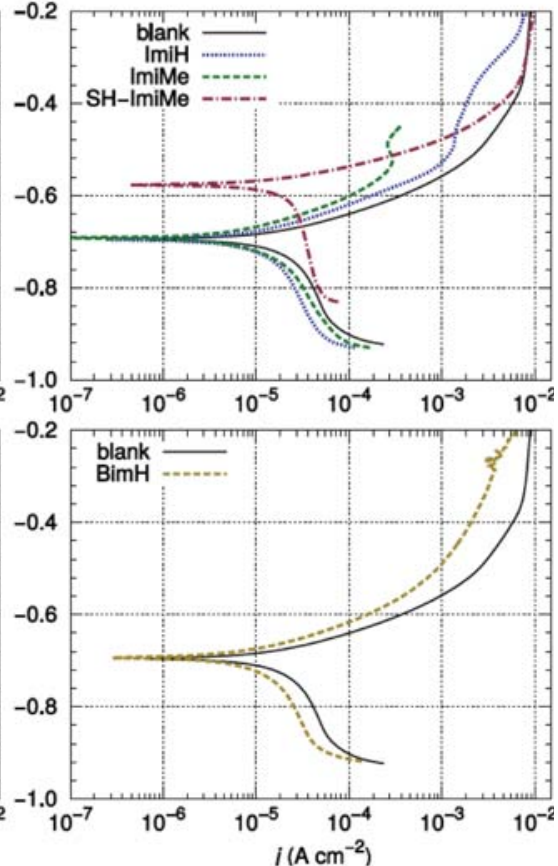

Figure 5. Potentiodynamic curves recorded for iron in 3 wt. $\% \mathrm{NaCl}$ solution, without and with addition of (a) $0.1 \mathrm{mM}$, (b) $1 \mathrm{mM}$, and (c) $10 \mathrm{mM}$ of either imidazole (ImiH), 1-methyl-imidazole (ImiMe), 1-methyl-2-mercapto-imidazole (SH-ImiMe), benzimidazole (BimH), or 2-mercaptobenzimidazole (SH-BimH) inhibitor. Curves for imidazole-based inhibitors (ImiH, ImiMe, SH-ImiMe) are shown in upper panels and those of benzimidazole-based inhibitors $(\mathrm{BimH}, \mathrm{SH}-\mathrm{BimH})$ in bottom panels. $\mathrm{dE} / \mathrm{dt}=1 \mathrm{mV} / \mathrm{s}$. 
fect in the anodic range of the polarization curve. At $10 \mathrm{~m}$ $\mathrm{M}$ inhibitor concentration a current peak at about $-0.5 \mathrm{~V}$ followed by a current density plateau appeared in the anodic branch in the presence of ImiH and ImiMe (Fig. 5c). For other inhibitors the increase in concentration does not seem to bring significant improvements in the potentiodynamic curves.

These results indicate that the inhibitors tested on iron act primarily as anodic inhibitors, i.e. affect primarily the anodic reaction. The changes in the cathodic branches are not so pronouncedly affected by the addition of inhibitor.

\section{1. 2. Immersion Test}

The efficiency of corrosion inhibitors was further examined by a long-term immersion test. Iron samples were immersed for 30 days in $100 \mathrm{~mL}$ solutions of $3 \mathrm{wt} . \%$ $\mathrm{NaCl}$ containing $1 \mathrm{mM}$ concentrations of either ImiH, ImiMe, SH-ImiMe, BimH, or SH-BimH. The resulting macro- and microscopic images of iron samples rinsed and dried after the immersion tests are shown in Fig. 6. In addition, values of mean surface roughness, $S_{\mathrm{a}}$, are denoted for each image. Iron samples before and after immersion in uninhibited $\mathrm{NaCl}$ solution are taken a control.

The macroscopic images of the samples largely differed: Fe sample in uninhibited solution was covered by an uneven light-grey and dark-green layer, probably corresponding to iron oxides. ImiH sample was dark grey, whilst ImiMe and BimH samples were light grey, giving a metallic appearance. For uninhibited and ImiMe samples the surface reveals grain structure of the substrate whilst other samples seem to be covered by coating layers. Both mercapto-containing samples were much darker than other samples, the coating appeared thicker, and contained some areas of lighter deposits.

The $S_{\text {a }}$ values, measured after the immersion, revealed large differences between the samples (Fig. 6). For ImiH, ImiMe and SH-BimH the $S_{\text {a }}$ values were smaller than that of control Fe sample immersed in $\mathrm{NaCl}(0.61$ $\mu \mathrm{m})$, whilst for BimH and, especially, SH-ImiMe the values were larger.

\section{1. 3. Chemical Composition and Speciation of Layers}

\section{1. 3. 1. Chemical Composition}

After immersion in $\mathrm{NaCl}$ solution for 30 days, the layer contained 18.2 at.\% $\mathrm{Fe}$ and 45.4 at.\% O, consistent with the formation of an oxide layer (Table 2). Carbon was present in 35.2 at.\%, ascribed to adventitious carbon. In our previous study performed on copper, ${ }^{1}$ the copper concentration at the surface decreased when inhibitor was present due to the formation of inhibitor layer. In the case of iron, however, the behaviour is different and the concentration of Fe is not decreased in the presence of inhibitor. Similar behaviour was observed for oxygen which
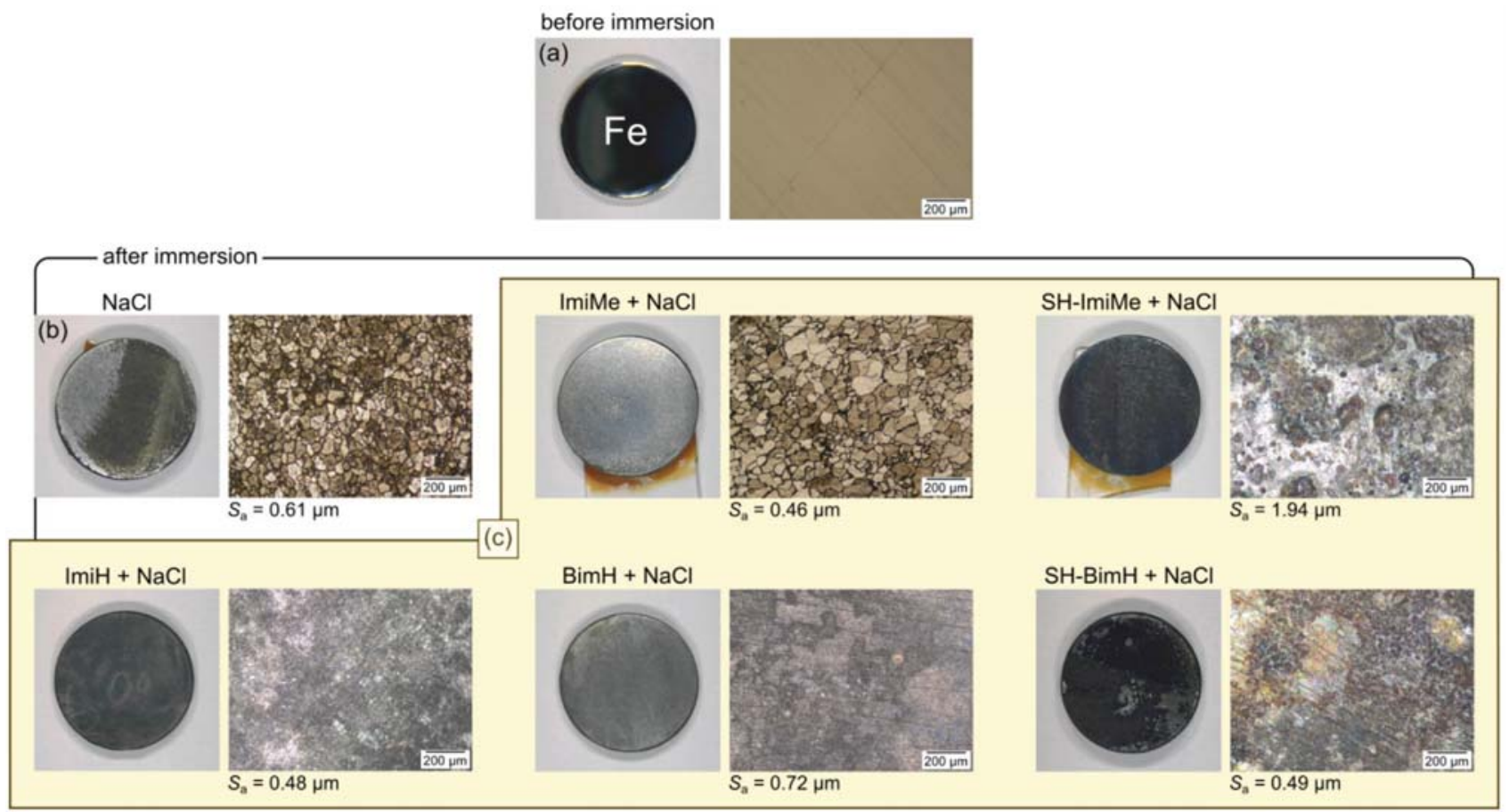

Figure 6. Macroscopic images and optical microscopy images of iron sample (a) before immersion and after 30 days immersion in $3 \mathrm{wt} \% \mathrm{NaCl}$ solution (b) without and (c) with the addition of $1 \mathrm{mM}$ of either imidazole (ImiH), 1-methyl-imidazole (ImiMe), benzimidazole (BimH), 1-methyl2-mercapto-imidazole (SH-ImiMe), or 2-mercaptobenzimidazole (SH-BimH). After immersion the specimens were rinsed with deionized water and dried with stream of nitrogen. The values of mean surface roughness, $S_{\mathrm{a}}$, as obtained by profilometer, are also stated. 
persisted in relatively high concentration at the surface even in the presence of inhibitor. Further, the concentration of carbon in the layer formed on copper in inhibitor solutions reached more than 60 at \%; in the case of iron the concentrations remained similar as in uninhibited sample (Table 2). A significant difference between inhibited and uninhibited iron surfaces is the presence of sulphur and nitrogen for mercapto-based compounds which indicates the bonding of the inhibitors to the surface as these elements originate from inhibitor compounds. Again, compared to copper, the concentrations are 2 to 4times smaller for iron. Another difference exists compared to inhibited copper: relatively small concentration of chlorine was detected at the iron surface only in the presence of BimH; in contrast, chlorine was detected in much higher concentrations (6.8 and 9.3 at\%) when $\mathrm{Cu}$ sample was immersed in ImiMe and ImiH inhibited solution, respectively, which were less protective than cuprous compounds. ${ }^{1}$

Although the general chemical composition of inhibited and uninhibited iron samples is quite similar, chemical speciation based on the high resolution spectra (Figs. 7 and 8) will show that the chemical environment changed in the presence of inhibitor.

\section{1. 3. 2. Chemical Speciation}

The chemical composition of the layers formed during 30-day immersion in $\mathrm{NaCl}$ solution with and without the addition of inhibitors was further studied by high-resolution spectra aiming to identify the chemical environment of elements and to relate particular chemical species to each other. First the metal peak is considered. The Xray photoelectron spectra of iron and its oxides is well known. ${ }^{6,31}$ Due to unpaired electrons in the valence band, iron compounds show a complex structure related to the multiplet splitting. ${ }^{32}$ The center of main $\mathrm{Fe} 2 \mathrm{p}_{3 / 2}$ peak in metallic iron is located at binding energy, $E_{\mathrm{b}}, 706.8 \mathrm{eV}$, whereas the second peak of lower intensity is located at $711.4 \mathrm{eV}$. In the case of Fe(II) oxide the multiplet splitting induces the appearance of peaks at $709.8 \mathrm{eV}$ and 711.9 $\mathrm{eV}$. Additionally, $\mathrm{Fe}$ (II) oxide shows the shake-up satellite at $715.0-715.5 \mathrm{eV}$, i.e. $\sim 5.5-6.0 \mathrm{eV}$ above the main peak.
In the case of $\mathrm{Fe}$ (III) oxide two peaks at $710.9 \mathrm{eV}$ and $712.7 \mathrm{eV}$ are observed due to multiplet splitting. The shake-up satellite is located $\sim 8.5 \mathrm{eV}$ above the main peak and is thus already in the range of $\mathrm{Fe} 2 \mathrm{p}_{1 / 2}$ peak. Therefore, several peaks in the Fe 2p XPS spectrum overlay in the range between $\sim 710 \mathrm{eV}$ and $\sim 713 \mathrm{eV}$ making the quantitative analysis complicated and unreliable without using appropriate standards. ${ }^{31}$ High resolution XPS spectra will be therefore addressed in a qualitative manner due to the complexity and large variety of species.
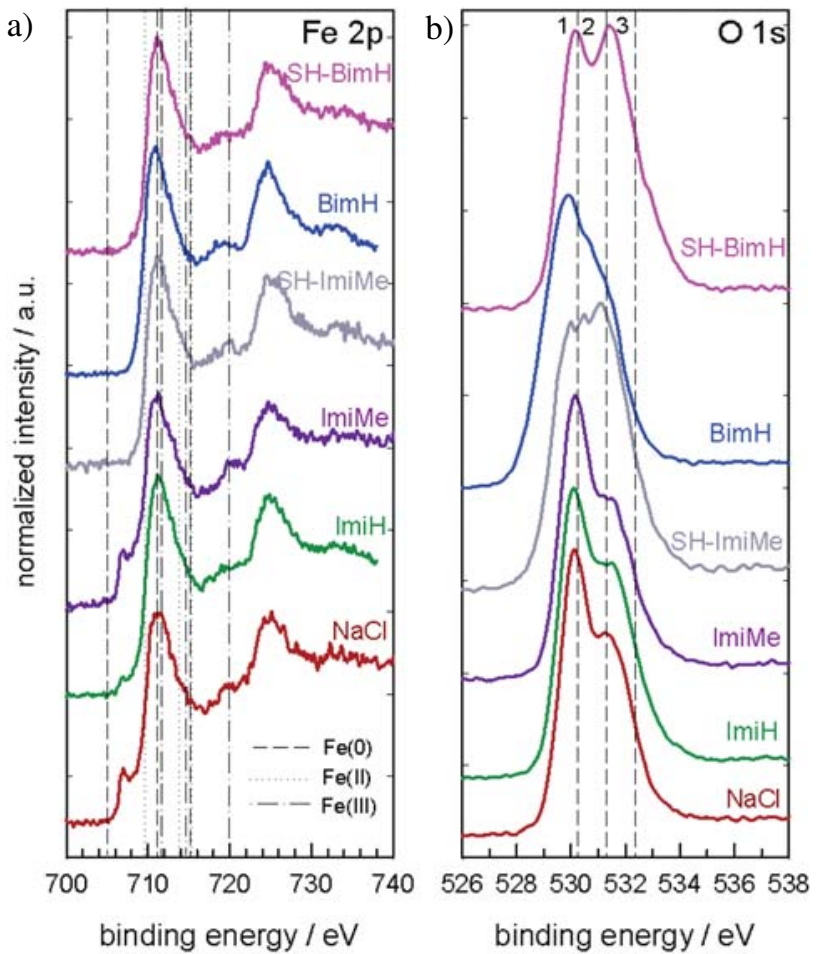

Figure 7: Normalized high resolution (a) Fe 2p and (b) O 1s spectra for layers formed during 30 days of immersion of iron in $3 \mathrm{wt} \% \mathrm{Na}$ $\mathrm{Cl}$ solution with and without the addition of $1 \mathrm{mM}$ imidazole (ImiH), 1-methyl-imidazole (ImiMe), 1-methyl-2-mercapto-imidazole (SHImiMe), benzimidazole (BimH) and 2-mercaptobenzimidazole (SHBimH). The take-off angle is 45 . Vertical dotted lines denote the position of peaks of reference compounds: (a) dashed: $\mathrm{Fe}(0)$, dotted: $\mathrm{Fe}(\mathrm{II})$ oxide, dash-dotted: $\mathrm{Fe}$ (III) oxide, (b) 1: $\mathrm{O}^{2-}, 2: \mathrm{OH}^{-}, 3: \mathrm{H}_{2} \mathrm{O}$.

Table 2. Chemical composition of the iron surface after 30 days immersion in $3 \mathrm{wt} \% \mathrm{NaCl}$ with and without addition of $1 \mathrm{mM}$ imidazole (ImiH) and its derivatives: 1-methyl-imidazole (ImiMe), 2-mercapto-1-methyl-imidazole (SH-ImiMe), benzimidazole (BimH), and 2-mercaptobenzimidazole (SH-BimH). The composition was derived from XPS survey spectra.

\begin{tabular}{lcccccc}
\hline Element & & \multicolumn{5}{c}{ Composition (atomic \%) } \\
& $\mathbf{N a C l}$ & $+\mathbf{I m i H}$ & + ImiMe & + SH-ImiMe & + BimH & + SH-BimH \\
\hline $\mathrm{Fe}$ & 19.3 & 20.2 & 42.9 & 20.4 & 30.1 & 20.6 \\
$\mathrm{O}$ & 45.4 & 52.6 & 18.4 & 45.0 & 53.2 & 44.7 \\
$\mathrm{C}$ & 35.3 & 23.7 & 38.7 & 25.0 & 14.9 & 26.9 \\
$\mathrm{Cl}$ & - & - & - & - & 1.9 & - \\
$\mathrm{N}$ & - & - & - & 2.1 & - & 1.4 \\
$\mathrm{~S}$ & - & - & - & - & - & 6.4 \\
$\mathrm{Si}$ & - & 3.5 & - & & - & - \\
\hline
\end{tabular}


Considering the $\mathrm{Fe} 2 \mathrm{p}$ spectra recorded after immersion (Fig. 7a) several features are observed: (i) peak related to metallic iron at $706.8 \mathrm{eV}$ appears only at the surface of Fe immersed in uninhibited $\mathrm{NaCl}$ solution and in solutions inhibited by ImiH and ImiMe. In the latter two samples the layers formed during immersion were obviously not thick enough to prevent the metal signal to be identified, or iron is subjected to continuous dissolution revealing metal sites. For other inhibitors the metal peak could not be identified indicating full coverage of the metal surface by the layer. The most intense peak in the spectra was for all samples located at $\sim 711 \mathrm{eV}$ indicating the formation of mixed $\mathrm{Fe}(\mathrm{II})$ and $\mathrm{Fe}$ (III) oxides. Two satellite peaks are characteristic of iron oxides - at $\sim 715 \mathrm{eV}$ for $\mathrm{Fe}$ (II) oxide and at $\sim 721 \mathrm{eV}$ for Fe(III) oxide. Both peaks are observed in experimental spectra (Fig. 7a).

The peak for oxygen can be resolved into three component peaks, ascribed to oxide, hydroxide and adsorbed water (denoted by lines 1-3 in Fig. 7b). In all the cases there were two peaks: the first located at $\sim 530 \mathrm{eV}$ ascribed to iron oxide, and the second at $531.3 \mathrm{eV}$ ascribed to hydroxide component. The intensity of oxygen peak was strong even in the presence of inhibitors (Table 2) proving that the inhibitor layer consists primarily of oxide, presumably mixed with inhibitor species, or that the inhibitor layer formed was not thick enough to hide the presence of underlying oxide.
Carbon $\mathrm{C} 1 \mathrm{~s}$, nitrogen $\mathrm{N} 1 \mathrm{~s}$ and sulphur $\mathrm{S} 2 \mathrm{p}$ peaks are important for understanding the chemical composition and environment of layers formed in chloride solutions containing organic inhibitors. In the present work the centre of the $\mathrm{C} 1 \mathrm{~s}$ peak was located at $285.0 \mathrm{eV}$ for both inhibitor-free and inhibitor containing solutions (Fig. 8a). This peak is assigned to carbon bonded to carbon or hydrogen $(\mathrm{C}-\mathrm{C}, \mathrm{C}-\mathrm{H})$. In imidazole-based inhibitors other bonds should be taken into account (denoted by lines 1-5 in Fig. 8a): carbon bonded to pyrrole nitrogen $(\mathrm{C}-\mathrm{N})$ at $286.1 \mathrm{eV}$, and carbon bonded to pyridine nitrogen $(\mathrm{C}=\mathrm{N})$ at $287.5 \mathrm{eV} .{ }^{1}$ Bonding between carbon and oxygen is also possible: the centres of the $\mathrm{C}-\mathrm{O}$ and $\mathrm{C}=\mathrm{O}$ peaks are located at mean $E_{\mathrm{b}}$ values of $286.5 \mathrm{eV}$ and $288.4 \mathrm{eV}$, respectively. In mercapto compounds the $\mathrm{C}-\mathrm{S}$ should be also taken into account but no specific peak related to $\mathrm{C}-\mathrm{S}$ bonding was defined in literature.

In inhibitor-free chloride solution the peak at $285.0 \mathrm{e}-$ $\mathrm{V}$ was narrow indicating that $\mathrm{C}-\mathrm{C}$ and $\mathrm{C}-\mathrm{H}$ bonding originating from adventitious carbon is the prevailing bonding in carbon peak. In solutions containing inhibitor the broadening of the carbon peak width occurred (Fig. 8a). The broadening is related to the increasing contribution of different carbon species bonded to other elements, i.e. nitrogen, oxygen and, presumably, sulphur, as described above. Layers formed in the BimH, SH-ImiMe and SH-BimH solutions show another peak at $286.1 \mathrm{eV}$. As in these layers nitrogen
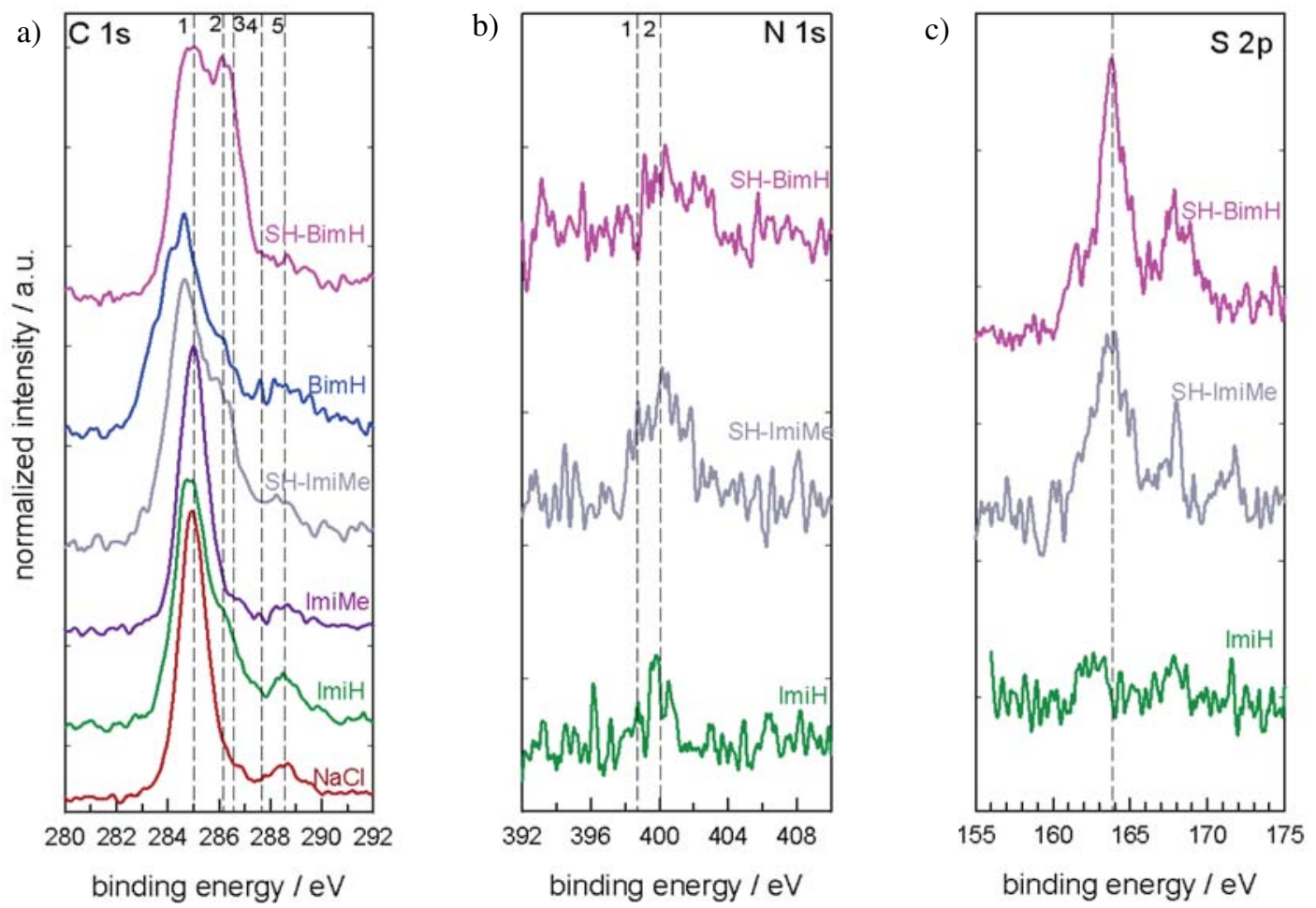

Figure 8: Normalized high resolution (a) C 1s, (b) N 1s and (c) S 2p XPS spectra for layers formed during 30 days of immersion of iron in 3 wt.\% $\mathrm{NaCl}$ solution with and without the addition of $1 \mathrm{mM}$ imidazole (ImiH), 1-methyl-imidazole (ImiMe), 1-methyl-2-mercapto-imidazole (SH-Imi$\mathrm{Me})$, benzimidazole (BimH) and 2-mercaptobenzimidazole (SH-BimH). The take-off angle is 45. Vertical dotted lines denote the position of peaks of reference compounds: (a) 1: C-C, C-H, 2: C-N (C-S), 3: C-O, 4: C=N, 5: $\mathrm{COO}^{-}$, (b) 1: C=N-C, 2: C-NH-C, and (c) S 2p $\mathrm{p}_{3 / 2} / \mathrm{S} 2 \mathrm{p}_{1 / 2}$. 
and sulphur are detected (Table 2), this peak can be related to the $\mathrm{C}-\mathrm{N}$ and presumably $\mathrm{C}-\mathrm{S}$ bonding.

Nitrogen was present only at the surface of the layer formed in a solution containing mercapto-based imidazoles (Fig. 8b, Table 2); for comparison, spectrum recorded in the layer formed in ImiH solution is given. In the case of copper, nitrogen was identified in much higher concentrations in layers formed in the presence of all inhibitors except ImiH. ${ }^{1}$ This is the main difference between inhibited iron and copper. A weak nitrogen 1s peak at iron surface is centred at $400 \mathrm{eV}$, preceded by a smaller peak at $398.8 \mathrm{eV}$. The presence of two peaks may be ascribed to the presence of single and double bonds, $\mathrm{C}-\mathrm{N}$ and $\mathrm{C}=\mathrm{N}$.

The sulphur $\mathrm{S} 2 \mathrm{p}$ spectrum comprises $\mathrm{S} 2 \mathrm{p}_{3 / 2}$ and $2 \mathrm{p}_{1 / 2}$ peaks that differ by only $1.1 \mathrm{eV}$ and are not usually differentiated as two separate peaks. In the layers formed in the presence of mercapto-based inhibitors a single peak was formed, centred at $163.8 \mathrm{eV}$ (Fig. 8c), in agreement with values reported for complexes formed between mercapto compounds and metals between $162.2 \mathrm{eV}$ and $164.4 \mathrm{eV}{ }^{1}$ For comparison, spectrum recorded in the layer formed in ImiH solution is given.

Chlorine peak was detected at low intensity only at the surface exposed to benzimidazole and may be related to adsorption of chloride ions at the surface and/or formation of oxychloride compound with a low chlorine content.

\section{1. 4. Structure of the Layers}

Angle-resolved XPS analysis was performed on uninhibited and inhibited iron surfaces. In contrast to copper, where due to intense nitrogen and sulphur XPS peaks such analysis brought about important conclusions regarding the structure of the layer, in the case of iron the com- parative analysis did not provide sufficient data to postulate a specific structure of the inhibitor layer. Several features were observed: (i) in $\mathrm{Fe} 2 \mathrm{p}$ spectra the metal part at $706.8 \mathrm{eV}$ decreased compared to oxide part at $\sim 711 \mathrm{eV}$ indicating that the latter is enriched at the outer surface of the layer, and (ii) in $\mathrm{O} 1 \mathrm{~s}$ spectra the hydroxide part at $531.3 \mathrm{eV}$ also increased compared to oxide part at $\sim 530.0$ $\mathrm{eV}$ indicating the surfaces is enriched in hydroxide species (results not shown). For $\mathrm{C} 1 \mathrm{~s}$ no significant difference were observed depending on the analysing angle, whilst for $\mathrm{N} 1 \mathrm{~s}$ and $\mathrm{S} 2 \mathrm{p}$ spectra the intensity of the signal was too low to allow conclusive angle-resolved analysis. Based on these results it can be stated that the layer formed on iron in inhibited solution is mainly iron oxide which contains species originating from inhibitor molecules, i.e. mixed oxide-inhibitor layer.

\section{2. Computational Results}

In this section the adsorption bonding of inhibitor molecules to $\mathrm{Fe}(110)$, as scrutinized with DFT calculations, is described. For each molecule several different adsorption modes were considered and below only the most stable identified mode per molecule and per adsorption type is considered. Iron surfaces are chemically reactive enough to disturb the molecular $\pi$ system and to break molecular X-H bonds. ${ }^{2,12}$ Hence, considered molecules can chemisorb to $\mathrm{Fe}(110)$ as standing up or lying down in neutral (non-dissociative) or dehydrogenated (dissociative) forms.

\section{2. 1. Adsorption Bonding of Neutral Molecules}

In this section the chemisorption bonding of neutral (intact) inhibitor molecules is described. Optimized struc-

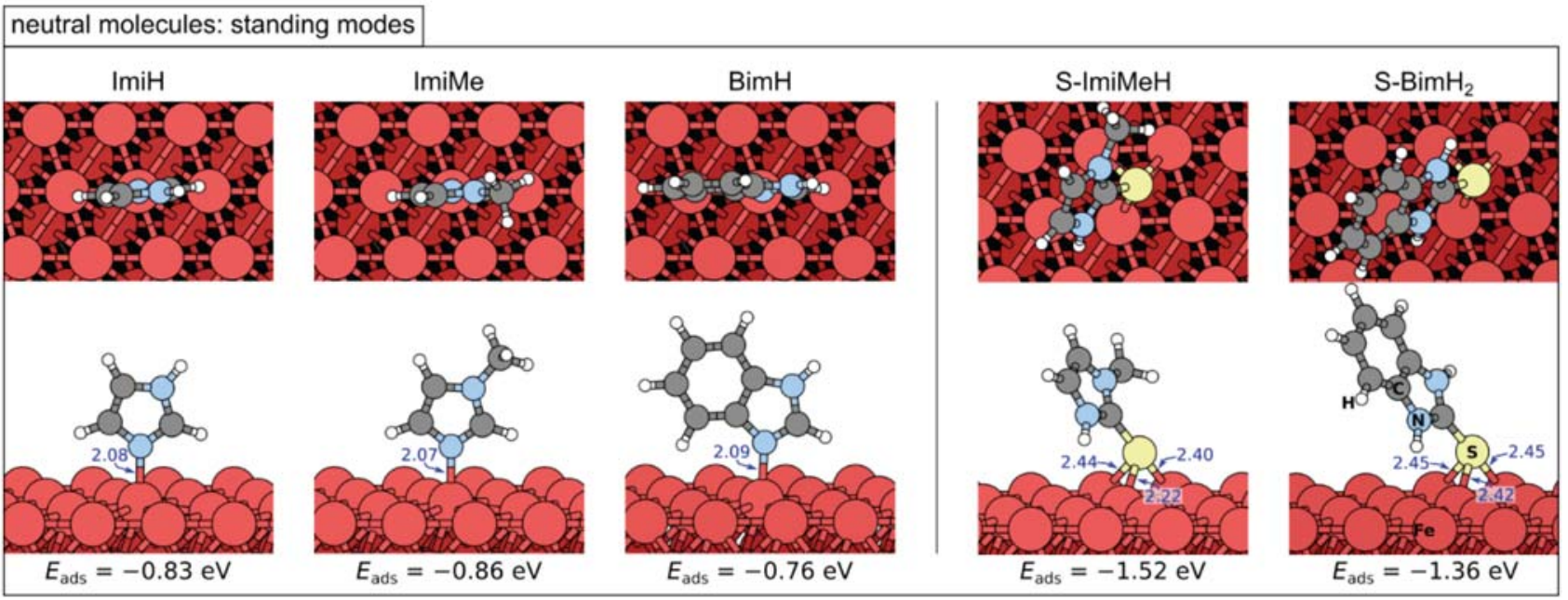

Figure 9. Top and perspective views of optimized standing molecular adsorption modes on Fe(110). From left to right: imidazole (ImiH), 1-methylimidazole (ImiMe), benzimidazole (BimH), and thione forms of 1-methyl-2-mercapto-imidazole (S-ImiMeH) and 2-mercaptoimidazole (S-Bim$\mathrm{H}_{2}$ ). Adsorption energies and molecule-surface bond lengths ( $\mathrm{N}-\mathrm{Fe}$ and $\mathrm{S}-\mathrm{Fe}$ ), calculated at 1/20 ML coverage, are also stated. Color coding of atoms is the following: $\mathrm{H}$ is white, $\mathrm{C}$ is gray, $\mathrm{N}$ is sky-blue, $\mathrm{S}$ is yellow, and $\mathrm{Fe}$ is reddish with color becoming darker as going from surface toward the bulk. 
tures of the standing and lying adsorption modes are shown in Figs. 9 and 10, respectively.

\section{2. 1. 1. Standing Adsorption Modes}

In the standing modes (Fig. 9), the three non-mercapto molecules bond with the pyridine $\mathrm{N} 3$ atom on top of a single $\mathrm{Fe}$ atom and 1-methyl-imidazole (ImiMe) bonds the strongest among the three molecules, but otherwise the bonding differences are small, being $-0.83,-0.86$, and $-0.76 \mathrm{eV}$ for ImiH, ImiMe, and $\mathrm{BimH}$, respectively. Benzimidazole $(\mathrm{BimH})$ thus binds the weakest, despite being the softest, i.e., it has the smallest HOMO-LUMO gap among the three molecules. ${ }^{2,33}$ An opposite behavior was observed for triazoles, where benzotriazole bonds slightly stronger than triazole to $\mathrm{Cu}(111) \cdot{ }^{34}$ In accordance with the bonding energy trend the $\mathrm{N}-\mathrm{Fe}$ molecule-surface bond length follows the $\operatorname{BimH}(2.09 \AA)>\operatorname{ImiH}(2.08 \AA)>$ ImiMe $(2.07 \AA)$ order, i.e., stronger adsorption bond corresponds to shorter bond length. The analogous bonding trend among the three molecules was also observed on $\mathrm{Cu}(111)$ surface and the reason that the $\mathrm{BimH}$ binds the weakest was attributed to steric hindrance of the bottommost $\mathrm{H}$ atom of benzene ring, which is too close to the surface. $^{2}$

The adsorption of mercapto-molecules is considered only in thione tautomer forms, because we find that thiols dissociate ( $\mathrm{S}-\mathrm{H}$ bond cleavage) barrier-less during adsorption. In the standing modes, thiones adsorb via the $\mathrm{S}$ atom slightly asymmetrically onto the long-bridge site ${ }^{\mathrm{d}}$ thus bonding to three surface $\mathrm{Fe}$ atoms. 2-mercapto-1methyl-imidazole $(\mathrm{S}-\mathrm{ImiMeH})$ binds by about $0.1 \mathrm{eV}$ stronger than 2-mercaptobenzimiazole $\left(\mathrm{S}-\mathrm{BimH}_{2}\right)$ and correspondingly also the $\mathrm{S}-\mathrm{Fe}$ bonds of the former are shorter than that of the latter. As for the comparison between the standing mercapto and non-mercapto molecules, it is evident that the S-surface bonding of mercapto molecules is by about $0.6 \mathrm{eV}$ stronger than the $\mathrm{N}$-surface bonding of non-mercapto molecules.

\section{2. 1. 2. Lying Adsorption Modes}

In the lying adsorption modes all the ring $\mathrm{C}$ and $\mathrm{N}$ atoms form bonds with the surface (Fig. 10). In addition, mercapto-molecules bond also with the $\mathrm{S}$ atom, which is adsorbed over the long-bridge site. Similar as for the standing modes, also in the lying modes the mercapto-molecules bond significantly stronger than non-mercapto molecules. 2-mercapto-1-methyl-imidazole again bonds the strongest $(-1.60 \mathrm{eV})$ and 2-mercaptobenzimiazole binds by about $0.1 \mathrm{eV}$ less.

Comparison of adsorption energies of standing and lying modes (cf. Figs. 9 and 10) reveals that for ImiH and ImiMe the two modes are of similar stability $\left(E_{\text {ads }} \approx-0.85\right.$ $\mathrm{eV}$ ), but for other molecules the lying modes are more stable. This trend can be, in part, attributed to molecular size. ImiH and ImiMe are the smallest and bond only with the imidazole ring to $\mathrm{Fe}(110)$. In addition, $\mathrm{BimH}$ bonds also with the benzene ring and thus binds by $0.4 \mathrm{eV}$ stronger than its standing form. Lying mercapto-molecules bind even stronger because they bond also with the reactive $\mathrm{S}$ atom to the surface. The $\mathrm{N}$-surface and $\mathrm{C}$-surface bond lengths of the lying molecules are about $2 \AA$, thus being characteristic of chemisorption.

\section{2. 2. Adsorption Bonding of Dehydrogenated Molecules}

$\mathrm{Fe}$ is a chemically reactive metal and it was shown that its surfaces can break the $\mathrm{N}-\mathrm{H}$ and $\mathrm{C}-\mathrm{H}$ bonds of imidazole. In particular, in the previous publication of one of us, ${ }^{12}$ it was shown that the breaking of the $\mathrm{C} 2-\mathrm{H}$

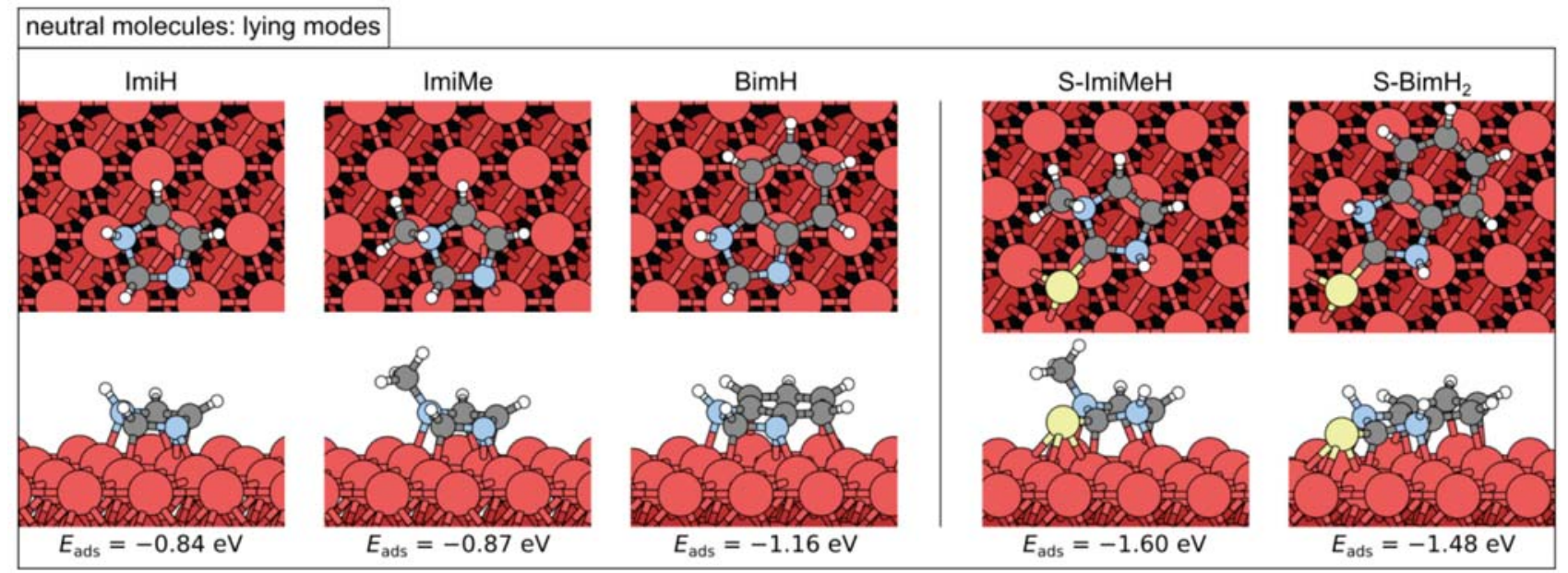

Figure 10. As in Figure 8, but for lying adsorption modes.

\footnotetext{
${ }^{\mathrm{d}}$ See Fig. 2 for definition of the short- and long-bridge sites.
} 
bond of imidazole on $\mathrm{Fe}(100)$ is particularly easy and it involves the transformation of the standing $\mathrm{N} 3$ bonded imidazole to a meta-stable tilted form that bonds with $\mathrm{N} 3+\mathrm{C} 2$ atoms to the surface (the energy barrier for this transformation is $0.3 \mathrm{eV}$ ). This transformation is then quickly followed by the cleavage of the $\mathrm{C} 2-\mathrm{H}$ bond (the corresponding energy barrier is only $0.03 \mathrm{eV}$ ) resulting into standing $\mathrm{C} 2+\mathrm{N} 3$ bonded dehydrogenated imidazole. ${ }^{12}$ This type of dehydrogenated molecules is considered in section 3.2.2.1 below. On the other hand, the cleavage of the $\mathrm{N} 1-\mathrm{H}$ bond of imidazole was found to be less easy and it proceeds from lying imidazole and results in the lying N1 dehydrogenated imidazole: the corresponding energy barrier on $\mathrm{Fe}(100)$ is $0.9 \mathrm{eV} .^{12}$ This type of dehydrogenated molecules are considered in section 3.2.2.2 below.

\section{2. 2. 1. Standing Dehydrogenated Adsorption Modes}

Optimized structures of standing dehydrogenated molecules are displayed in Fig. 11; dissociative chemisorption $\left(E_{\mathrm{ads}}^{\text {diss }}\right)$ and binding energies $\left(E_{\mathrm{b}}\right)$ are also stated. Shown non-mercapto molecules are all $\mathrm{C} 2$ dehydrogenated (labeled as $\mathrm{Mol}_{\mathrm{C} 2}$ ) and bond via $\mathrm{C} 2$ and $\mathrm{N} 3$ atoms to the surface. Top-view plots reveal that molecular planes are perpendicular to the long-bridge direction with the midpoint of the $\mathrm{C} 2-\mathrm{N} 3$ bond over the midpoint of the long-bridge. Dissociative chemisorption energies are about $-2.0 \mathrm{eV}$ for all the three molecules, thus being considerably more exothermic than the non-dissociative $E_{\text {ads }}$, the latter being about $-0.8 \mathrm{eV}$. Dehydrogenation energies, calculated by Eq (8), are thus about $-1.2 \mathrm{eV}$. These molecules, however, bond way stronger to the surface than the $E_{\text {ads }}^{\text {diss }}$ values indicate and the corresponding binding energies, calculated by Eq (5), are about $-4.1 \mathrm{eV}$.
In contrast to non-mercapto molecules, mercapto molecules cannot dehydrogenate at the $\mathrm{C} 2$ atom, because they have $\mathrm{S}$ instead of $\mathrm{H}$ bonded to the $\mathrm{C} 2$. But they can dehydrogenate via cleavage of the N3-H bond (note that for $\mathrm{S}-\mathrm{BimH}_{2}$ the $\mathrm{N} 1$ and $\mathrm{N} 3$ are symmetry equivalent).

The corresponding dissociative chemisorption energies are more exothermic than for non-mercapto molecules, being -2.45 and $-2.29 \mathrm{eV}$ for 2-mercapto-1-methylimidazole and 2-mercaptobenzimidazole, respectively. In the dehydrogenated state, the S-ImiMe and S-BimH bond via $\mathrm{N} 3$ and $\mathrm{S}$ atoms to the surface, with the $\mathrm{N} 3$ bonded on top of an Fe atom and with the S located at the short-bridge site thus forming bonds with two bridge Fe atoms. The reason for more exothermic $E_{\text {ads }}^{\text {diss }}$ of mercapto molecules compared to non-mercapto molecules can be, in part, attributed to weaker N3-H bond (about $3.8 \mathrm{eV}$ ) compared to the $\mathrm{C} 2-\mathrm{H}$ bond of non-mercapto molecules (about 5.1 $\mathrm{eV})$. Despite the $E_{\mathrm{ads}}^{\mathrm{diss}}$ being more exothermic than for nonmercapto molecules, the S-ImiMe and S-BimH bond weaker to the surface than non-mercapto molecules, and the corresponding binding energies $\left(E_{\mathrm{b}}\right)$ are about $-3.2 \mathrm{eV}$ (to be compared to $-4.1 \mathrm{eV}$ for non-mercapto molecules).

\section{2. 2. 2. Lying Dehydrogenated Adsorption Modes}

Optimized structures of lying dehydrogenated molecules are shown in Fig. 12; dissociative chemisorption $\left(E_{\text {ads }}^{\text {diss }}\right)$ and binding energies $\left(E_{\mathrm{b}}\right)$ are also stated. Shown dehydrogenated molecules have the $\mathrm{N}-\mathrm{H}$ bond cleaved, which is $\mathrm{N} 1-\mathrm{H}$ for non-mercapto molecules (labeled as $\mathrm{Mol}_{\mathrm{N} 1}$ ) and $\mathrm{N} 3-\mathrm{H}$ for mercapto-molecules (for S-BimH the $\mathrm{N} 1$ and $\mathrm{N} 3$ are symmetry equivalent). Note that $\mathrm{ImiMe}_{\mathrm{N} 1}^{\mathrm{w} / \mathrm{O}-\mathrm{H}}$ cannot exist, because ImiMe does not have any $\mathrm{N}-\mathrm{H}$ bond.

For all considered molecules, except the S-BimH, the lying dehydrogenated modes are less stable than the

dehydrogenated molecules: standing modes

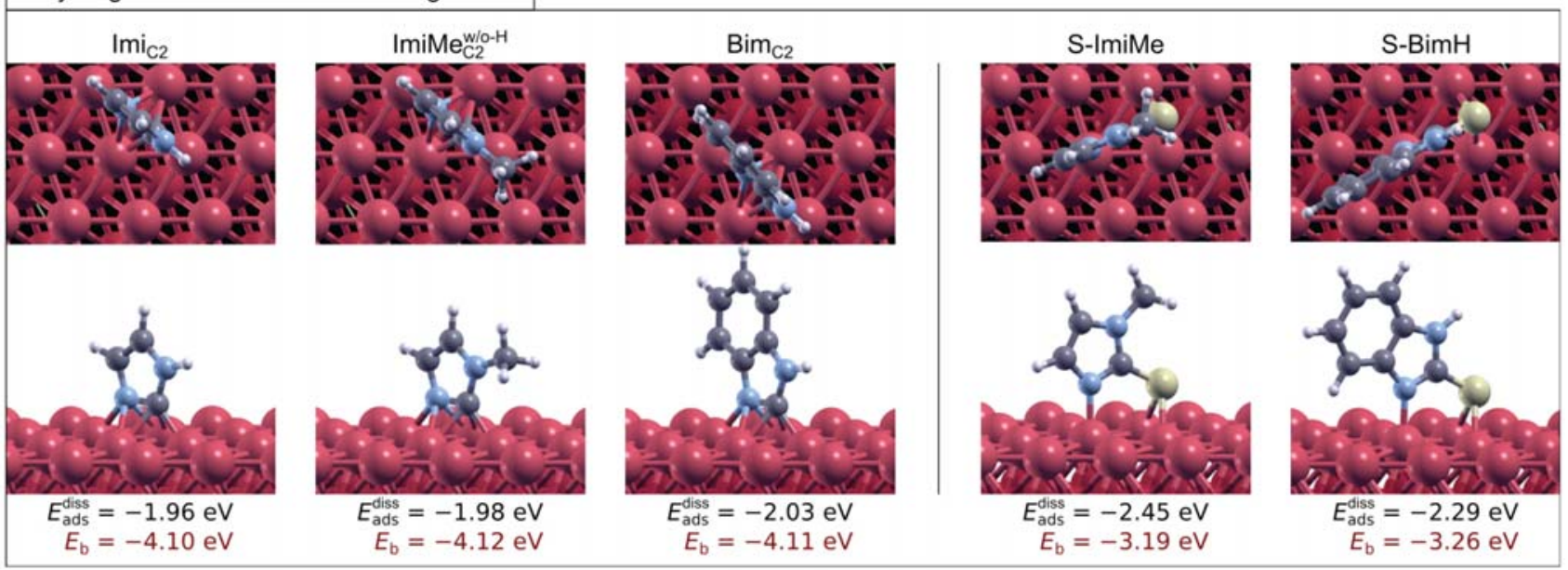

Figure 11. "Dehydrogenated" standing adsorption modes on $\mathrm{Fe}(110)$; non-mercapto molecules lack the $\mathrm{H}$ at C2 atom, whereas mercapto molecules are in thiolate form (which can be seen as thione lacking the $\mathrm{H}$ at N3 or as thiol lacking the $\mathrm{H}$ at $\mathrm{S}$ ). Dissociative adsorption energies $\left(E_{\text {ads }}^{\text {diss }}\right.$ ), corresponding to the $\mathrm{MolH}_{(\mathrm{g})} \rightarrow \mathrm{Mol}_{(\mathrm{ads})}+\mathrm{H}_{(\mathrm{ads})}$ process, and the Mol-Fe(110) binding energies $\left(E_{\mathrm{b}}\right)$ are also stated. 


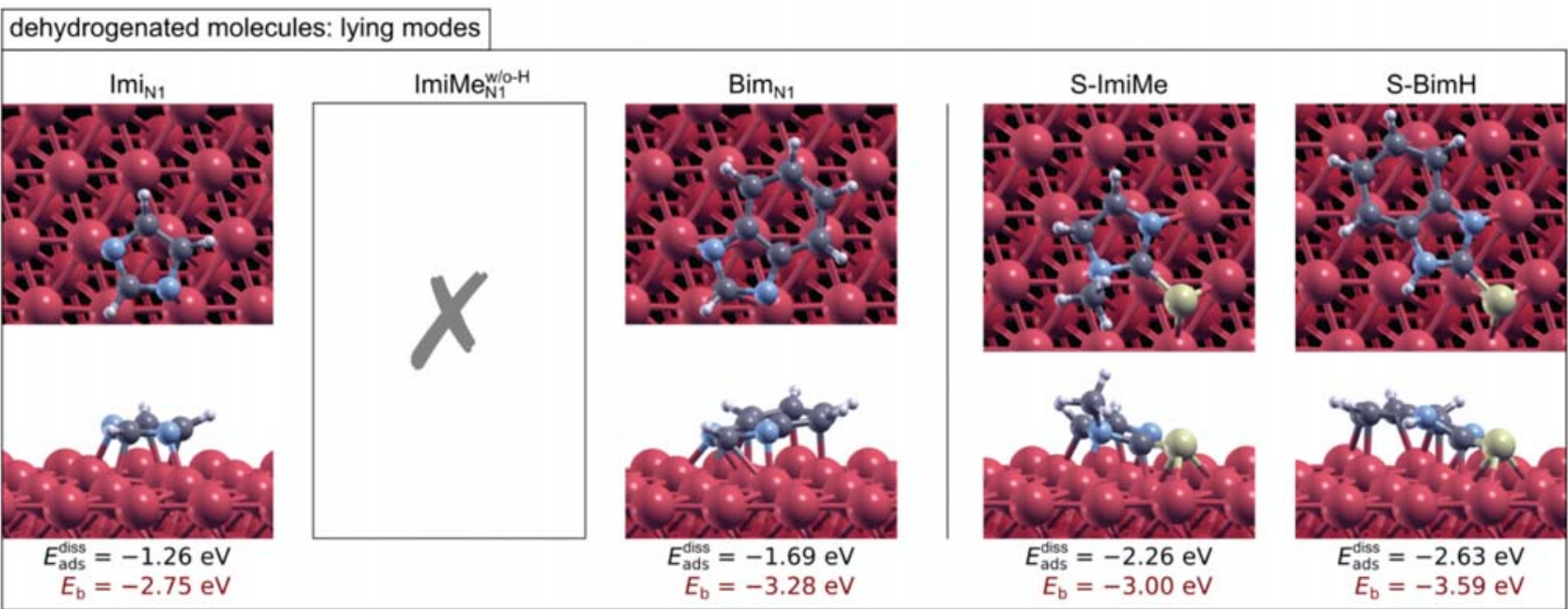

Figure 12. "Dehydrogenated" lying adsorption modes on Fe(110); non-mercapto molecules lack the H at N1 atom, whereas mercapto molecules are in thiolate form.

standing modes. Notable exception is the lying mode of $\mathrm{S}$-BimH, with the $E_{\text {ads }}^{\text {diss }}$ of $-2.63 \mathrm{eV}$, which is the most stable identified adsorption mode among all the currently considered cases (cf. Figs. 9-12).

Comparison of Figs. 10 and 12 reveals that the most stable identified lying modes of imidazole and benzimidizaole are analogous between neutral and dehydrogenated molecules, whereas for mercapto molecules the most stable identified lying neutral and dehydrogenated modes are rotated by about $90^{\circ}$ around the surface normal with respect to each other, i.e., neutral lying molecules have the $\mathrm{S}-\mathrm{C}$ bond oriented along the long-bridge direction, whereas dehydrogenated molecules have the $\mathrm{S}-\mathrm{C}$ bond oriented perpendicular to the long-bridge direction.

\section{Conclusions}

The effect of mercapto and methyl groups on the adsorption bonding of imidazole and benzimidazole based inhibitors on $\mathrm{Fe}(110)$ surface and their efficiency of iron corrosion in $3 \mathrm{wt} . \% \mathrm{NaCl}$ solution was studied by means of explicit DFT calculations and corrosion experiments, respectively. At $1 \mathrm{mM}$ concentration, the highest inhibition efficiency $(69 \%)$ was achieved by 1 -methyl-imidazole, and the lowest ( $8 \%$ ) by imidazole. Other tested inhibitors, 2-mercaptobenzimidazole, benzimidazole and 2-mercapto-1-methyl-imidazole, showed similar efficiencies $(41-57 \%)$. At $10 \mathrm{mM}$, the differences between inhibitors were smaller and ranged between 41 and $72 \%$. For 2-mercaptobenzimidazole the solubility below $10 \mathrm{mM}$ prevented it from being tested at this concentration. Inhibitors acted primarily as anodic inhibitors due to the formation of surface layer. Its composition corresponds mainly to oxidized iron, namely a mixture of $\mathrm{Fe}(\mathrm{II})$ and $\mathrm{Fe}(\mathrm{III})$ oxide and hydroxides, which contains also species originating from inhibitor molecules, i.e. nitrogen and sulphur. Compared to inhibited copper, the concentration of the latter is much smaller, and, furthermore, is observed only for mercapto-containing inhibitors. In contrast to copper, where mercapto containing derivatives of imidazoles were beneficial for all concentrations tested, their inhibition of iron corrosion was advantageous compared to other derivatives only at low inhibitor concentration. Other inhibitors at $0.1 \mathrm{mM}$ were either inefficient or acted as activators. On the other hand, methyl-derivative of imidazole had a positive impact on inhibition of iron at all concentrations regardless whether imidazole or mercaptoimidazole were used. These results prove that the inhibition effect of given inhibitor is strongly dependent on the metal substrate and that the inhibition efficiency cannot be predicted for inhibitor per se without taking into account the characteristics of substrate. This issue is apparently not appreciated in the literature, because majority of computational studies of corrosion inhibitors rely solely on electronic parameters of inhibitor molecules without any consideration of the substrate whatsoever.

DFT calculations reveal that current inhibitor molecules bind stronger to iron than copper surfaces, but this is of no direct relevance to corrosion inhibition. Namely, iron is chemically more reactive than copper, thus it can be reasonably anticipated-on the basis of Hammer-Nørskov chemisorption model ${ }^{35}$-that it binds, in general, adsorbates stronger than copper. It is thus the relative adsorption bonding strength of inhibitors compared to that of corrosive species such as, chloride, that is relevant.

Current computational results and those obtained previously on copper reveal that the inhibitor-surface bonding, as important as it may be, is not sufficient to explain the trend of corrosion inhibition efficiency of the investigated inhibitors. Namely, the adsorption bonding of investigated inhibitors can be roughly classified into two 
types with non-mercapto molecules belonging to one and mercapto molecules to the other type. Non-mercapto molecules display less exothermic adsorption than mercapto molecules and bind through the $\mathrm{N}$-surface bonds (in the lying and/or dehydrogenated mode also via the $\mathrm{C}$-surface bonds), whereas mercapto molecules bond in addition also via the S-surface bonds. On this basis one can infer that mercapto inhibitors should be superior to non-mercapto inhibitors, which is correct only at low inhibitor concentration. Adsorption characteristics of non-mercapto molecules display insignificant differences between them (with the exception of lying benzimidazole on iron, which binds stronger), yet the experimentally observed inhibition efficiency differ significantly between them. In this respect the effect of methyl group is the most interesting and non intuitive, because on both copper and iron surfaces, 1-methyl-imidazole display similar adsorption characteristics as the imidazole, yet on copper the presence of methyl group is disadvantageous or even detrimental, whereas on iron it is beneficial.

\section{Acknowledgements}

The financial support of this work provided by the Slovenian Research Agency within the research grant P20393 is greatly appreciated. The authors thank Dr. Janez Kovač and Tatjana Filipič, BSc, for XPS measurements and Dunja Gustinčič, PhD student, for experimental help.

\section{References}

1. I. Milošev, N. Kovačević, J. Kovač, A. Kokalj, Corrosion Sci. 2015, 98, 107-118. http://dx.doi.org/10.1016/j.corsci.2015.05.006

2. N. Kovačević, I. Milošev, A. Kokalj, Corrosion Sci. 2015, 98, 457-470.

http://dx.doi.org/10.1016/j.corsci.2015.05.041

3. G. Bhargava, T. A. Ramanarayanan, I. Gouzman, E. Abelev, S. L. Bernasek, Corrosion Sci. 2009, 65, 308-317. http://dx.doi.org/10.5006/1.3319135

4. H. Amar, A. Tounsi, A. Makayssi, A. Derja, J. Benzakour, A. Outzourhit, Corrosion Sci. 2007, 49, 2936-2945. http://dx.doi.org/10.1016/j.corsci.2007.01.010

5. K. F. Khaled, Electrochim. Acta 2003, 48, 2493-2503. http://dx.doi.org/10.1016/S0013-4686(03)00291-3

6. K. Babic-Samardžija, C. Lupu, N. Hackerman, A. R. Barron, A. Luttge, Langmuir 2005, 21, 12187-12196. http://dx.doi.org/10.1021/la0517661

7. O. Olivares-Xometl, N. V. Likhanova, M. A. DomínguezAguilar, J. M. Hallen, L. S. Zamudio, E. Arce, Appl. Surf. Sci. 2006, 252, 2139-2152. http://dx.doi.org/10.1016/j.apsusc.2005.03.178

8. S. K. Mondal, S. R. Taylor, J. Electrochem. Soc. 2014, 161, C476-C485. http://dx.doi.org/10.1149/2.0191410jes

9. P. Morales-Gil, M. S. Walczak, R. A. Cottis, J. M. Romero, R. Lindsay, Corrosion Sci. 2014, 85, 109-114. http://dx.doi.org/10.1016/j.corsci.2014.04.003

10. O. Benali, L. Larabi, M. Trainsel, L. Gengembre, Y. Harek, Appl. Surf. Sci. 2007, 253, 6130-6139. http://dx.doi.org/10.1016/j.apsusc.2007.01.075

11. N. Kovačević, A. Kokalj, Mater. Chem. Phys. 2012, 137, 331-339. http://dx.doi.org/10.1016/j.matchemphys.2012.09.030

12. A. Kokalj, Corros. Sci. 2013, 68, 195-203. http://dx.doi.org/10.1016/j.corsci.2012.11.015

13. N. Kovačević, A. Kokalj, J. Phys. Chem. C, 2011, 115, 24189-24197 http://dx.doi.org/10.1021/jp207076w

14. N. Kovačević, A. Kokalj, Corros. Sci. 2013, 73, 7-17. http://dx.doi.org/10.1016/j.corsci.2013.03.016

15. J. Radilla, G. E. Negron-Silva, M. Palomar-Pardave, M. Romero-Romo, M. Galvan, Electrochim. Acta. 2013, 112, 577586, http://dx.doi.org/10.1016/j.electacta.2013.08.151

16. S. Sun, Y. Geng, L. Tian, S. Chen, Y. Yan, S. Hu, Corros. Sci. 2012, 63. 140-147. http://dx.doi.org/10.1016/j.corsci.2012.05.024

17. G. Bhargava, T. Ramanarayanan, S. L. Bernasek, Langmuir, 2010, 26, 215-219. http://dx.doi.org/10.1021/la9020355

18. D. Briggs, J. C. Rivière, Spectral interpretation. In: D. Briggs, M.P. Seah (Eds.), Practical Surface Analysis by XPS and AES, Chichester, New York, 1990.

19. J. P. Perdew, K. Burke, M. Ernzerhof, Phys. Rev. Lett. 1996, 77, 3865-3868. http://dx.doi.org/10.1103/PhysRevLett.77.3865

20. D. Vanderbilt, Phys. Rev. B 1990, 41, 7892-7895. http://dx.doi.org/10.1103/PhysRevB.41.7892

21. Ultrasoft pseudopotentials were taken from the Quantum Espresso Pseudopotential Download Page: http://www.quantum-espresso.org/pseudopotentials/, 2016, files: H.pbe-rrkjus.UPF, C.pberrkjus. UPF, N.pbe-rrkjus.UPF, S.pbe-van bm.UPF, and Fe.pbe-sp-van.UPF.

22. P. Giannozzi, S. Baroni, N. Bonini, M. Calandra, R. Car, C. Cavazzoni, D. Ceresoli, G. L. Chiarotti, M. Cococcioni, I. Dabo, A. D. Corso, S. de Gironcoli, S. Fabris, G. Fratesi, R. Gebauer, U. Gerstmann, C. Gougoussis, A. Kokalj, M. Lazzeri, L. Martin-Samos, N. Marzari, F. Mauri, R. Mazzarello, S. Paolini, A. Pasquarello, L. Paulatto, C. Sbraccia, S. Scandolo, G. Sclauzero, A. P. Seitsonen, A. Smogunov, P. Umari, R. M. Wentzcovitch, J. Phys.: Condens. Matter. 2009, 21, 395502, code available from http://www.quantum-espresso.org/. http://dx.doi.org/10.1088/0953-8984/21/39/395502

23. A. Kokalj, Chem. Phys. 2012, 393, 1-12. http://dx.doi.org/10.1016/j.chemphys.2011.10.021

24. L. Bengtsson, Phys. Rev. B 1999, 59, 12301-12304. http://dx.doi.org/10.1103/PhysRevB.59.12301

25. M. Methfessel, A. T. Paxton, Phys. Rev. B 1989, 40, 36163621. http://dx.doi.org/10.1103/PhysRevB.40.3616

26. H. J. Monkhorst, J. D. Pack, Phys. Rev. B 1976, 13, 51885192. http://dx.doi.org/10.1103/PhysRevB.13.5188 
27. A. Kokalj, J. Mol. Graph. Model., 1999, 17, 176-179, code available from http://www.xcrysden.org/. http://dx.doi.org/10.1016/S1093-3263(99)00028-5

28. ChemicalBook Inc., http://www.chemicalbook.com/ProductChemicalPropertiesCB8490256_EN.htm, 2015.]

29. B. Macdougall, M.J. Graham, in: P. Marcus (Ed.), Corrosion Mechanisms in Theory and Practice, Marcel Dekker, Inc., New York, Basel, 2002, pp. 189-216.

30. V. Brusic, in: J.W: Diggle (Ed.) Oxides and Oxides Films. Marcel Dekker, New York, 1972, pp. 1-80.
31. I. Milošev, H.-H. Strehblow, J. Biomed. Mater. Res. 2000, 52, 404-412.

32. T. J. Chuang, C.R. Bundle, K. Wandelt. Thin Solid Films 1978, 53, 19-27.

33. N. Kovacevic, A. Kokalj, Corros. Sci., 2011, 53, 909-921 http://dx.doi.org/10.1016/j.corsci.2010.11.016

34. A. Kokalj, N. Kovačević, S. Peljhan, M. Finšgar, A. Lesar, I. Milošev, ChemPhysChem, 2011, 12, 3547-3555.

35. B. Hammer, J. K. Nørskov, Adv. Catal., 2000, 45, 71-129 http://dx.doi.org/10.1016/S0360-0564(02)45013-4

\section{Povzetek}

V tej študiji smo s kombinacijo eksperimentalnih in računskih metod obravnavali imidazolne in benzimidazolne inhibitorje, ki vsebujejo metilno in/ali merkapto skupino. Eksperimentalni del študije obsega elektrokemijske meritve in enomesečni potopitveni test v $3 \%$ raztopini $\mathrm{NaCl}$, računski del pa eksplicitno obravnava podrobnosti vezave inhibitorja na površino železa na molekularnem nivoju z uporabo teorije gostotnega funkcionala (DFT). Eksperimetnalni podatki, dopolnjeni s 3D topografijo in rentgensko fotoelektronsko spektroskopijo, so bili osnova za izračun inhibicijske učinkovitosti in mehanizma inhibicije. Merkapto skupina v kombinaciji s metilno skupino ima pozitiven vpliv na inhibicijo korozije pri vseh testiranih koncentracijah. Pozitiven vpliv merkapto skupine v kombinaciji z benzenskim obročem pa ni tako izražen kot v kombinaciji z metilno skupino. Opaženo vedenje je v nasprotju s tistim, ki smo ga zasledili pri bakru, kjer je bil vpliv metilne skupine škodljiv, pri čemer je 1-metil-imidazol celo pospeševal korozijo pri koncentraciji $10 \mathrm{~m}-$ M. Po drugi strani pa je bil vpliv mekrapto skupine in benzenskega obroča vedno pozitiven. DFT izračuni so razkrili, da ima metilna skupina majhen vpliv na interakcije inhibitor-površina Fe, saj ni direktno vključena v vezavo molekula-površina. Nasprotno, prisotnost merkapto skupine povzroči nov tip interkacij molekula-površina, ki vključuje močno vez S-površina, posledično je adsorpcija inhibitorja preko merkapto skupine zato bolj eksotermna. 